\title{
قياس تأثير تقلبات أسعار النفط على الناتج المحلي الإجمالي في مصر خلال المدة (1990-2016)
}

\author{
بحث مستل من رسالة دكتور اه

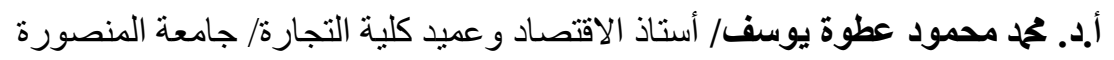

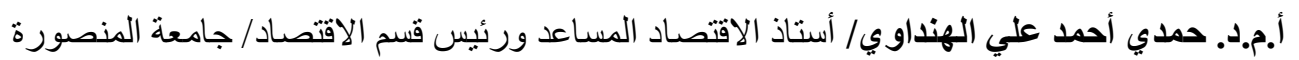

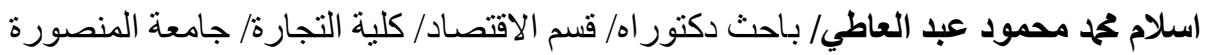 \\ الملخص. نؤثر تقلبات اسعار النفط على اغلب متغيرات الاقتصاد القومي لكل الدول وتكون هذه

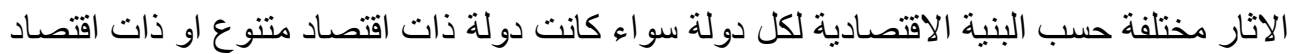

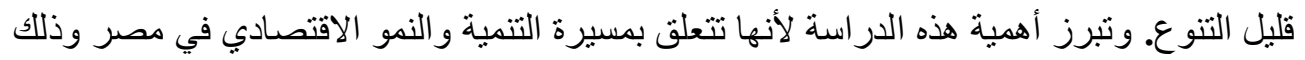

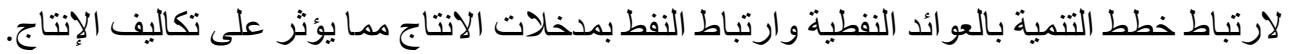

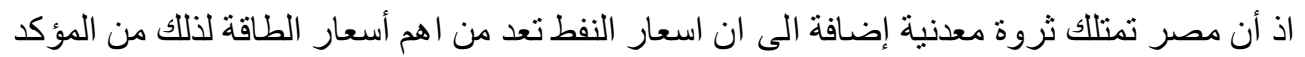

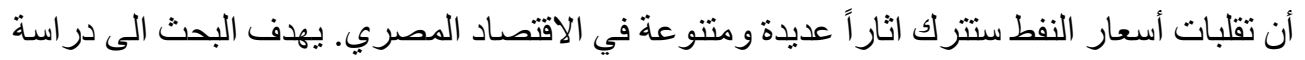

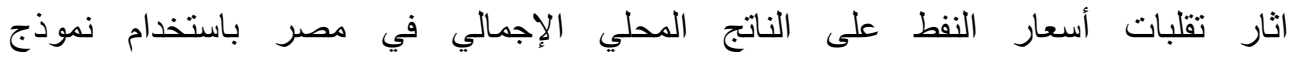 \\ (Autoregressive Distributed Lag) واختصاره (ARDL) خلال المدة (1990-2016). \\ و أظهرت نتائج التحليل القياسي وجود علاقة طويلة الاجل وموجية بين أسعار النفط و الناتج المحلي

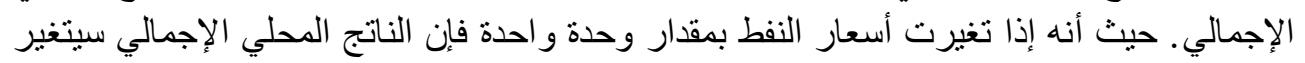 \\ بمقدار (0.85) وحدة.
}

Summary. Oil price fluctuations affect most of the variables of the national economy of all countries, and these effects are different according to the economic structure of each country, whether it is a country with a diversified economy or a economy with little diversity. The importance of this study is highlighted because it relates to the march of development and economic growth in Egypt, because development plans are linked to oil revenues and oil is linked to production inputs, which affects production costs. As Egypt possesses mineral wealth in addition to the fact that oil prices are among the most important energy prices, so it is certain that fluctuations in oil prices will leave many and varied effects in the Egyptian economy. The research aims to study the effects of oil price fluctuations on the gross domestic product in Egypt using the (Autoregressive Distributed Lag) model and its abbreviation (ARDL) during the period (1990-2016). The results of the benchmark analysis showed a positive and long-term relationship between oil prices and GDP. Whereas, if oil prices change by one unit, then the gross domestic product will change by $(0.85)$ units. 
المقدمة. تعد أسعار النفط هي الأكثر أهية بالنسبة للاول المصدرة والمستهلكة للنفط

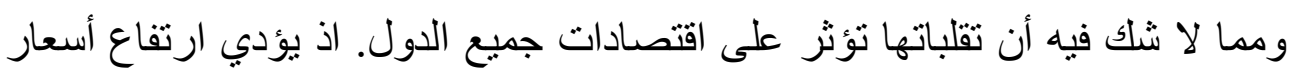

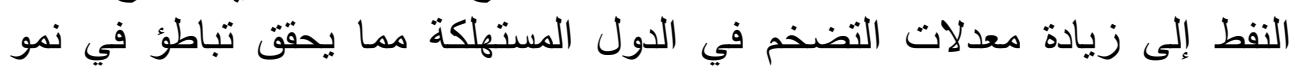

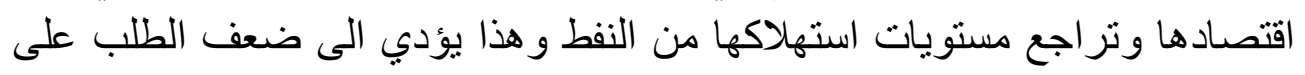

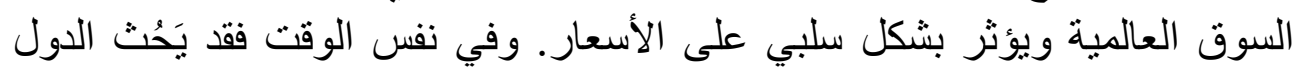

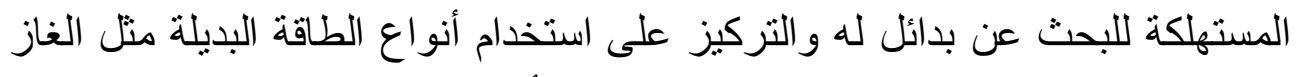

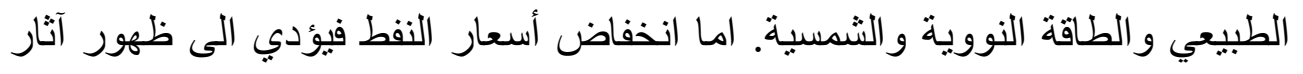

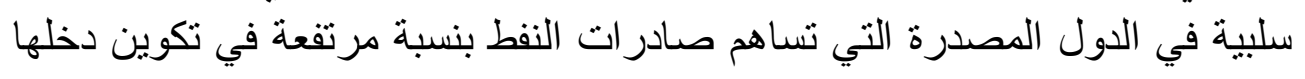

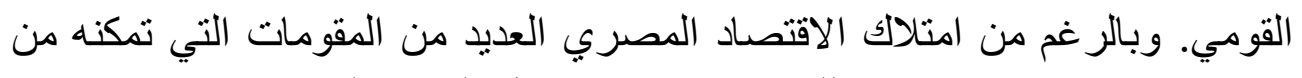

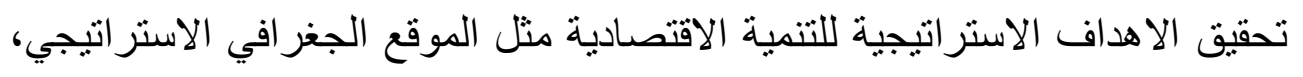

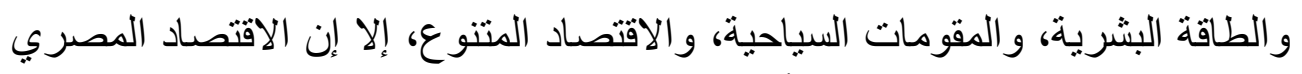

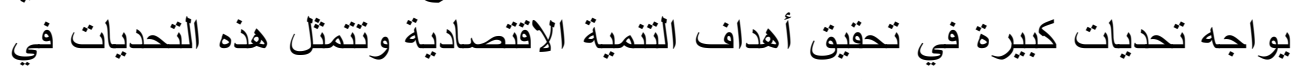

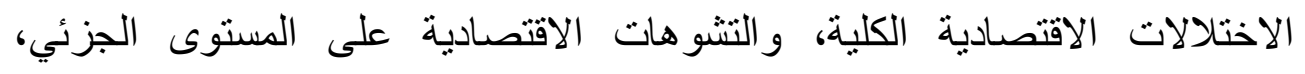

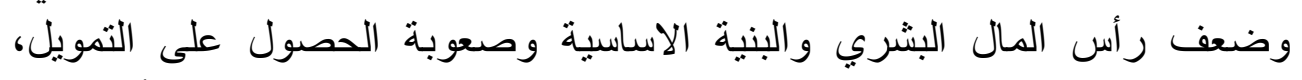

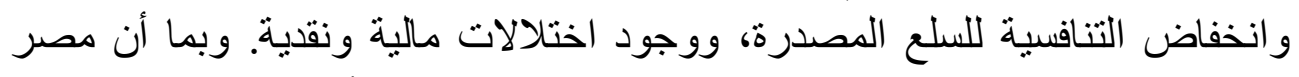

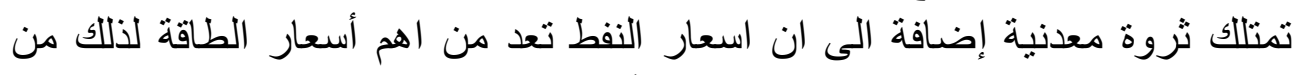

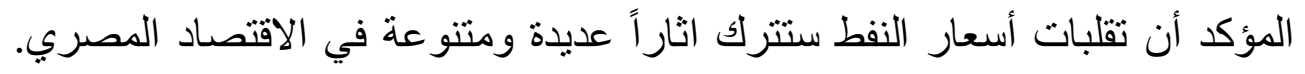

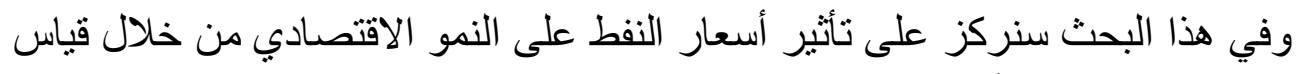
العلاقة بين تقلبات أسعار النفط ومعدل الناتج المحلي النئ الإجمالي خلال الددة (19902016) أهمية البحث: تعد تقلبات اسعار النفط من المشاكل المهمة التي تشغل تفكير الحكومات

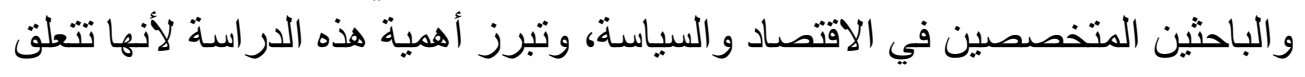

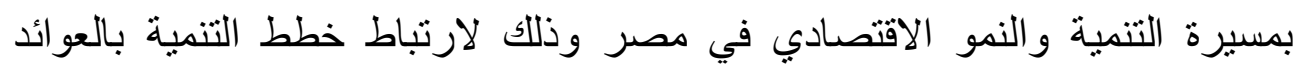

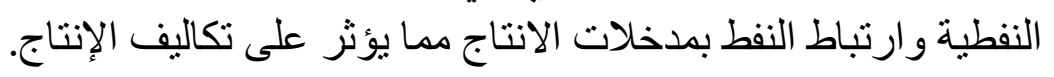

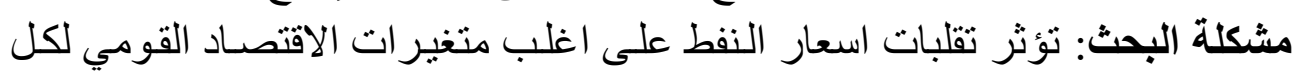

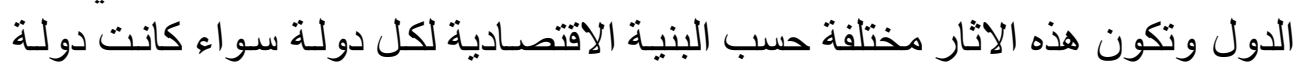

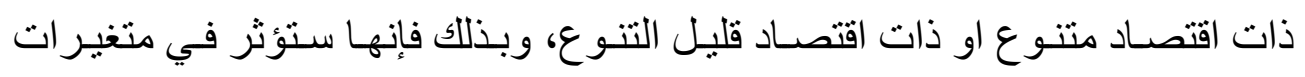

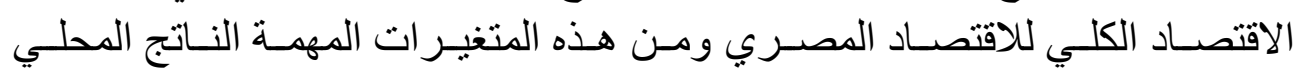
الإجمالي. أهداف البحث: يهدف البحث الى دراسة اثار تقلبات أسعار النفط على الناتج المحلي

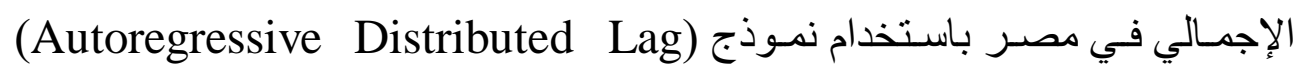
واختصاره (ARDL) خلال الددة (1990-2016). 
فرضية البحث: يفترض البحث ان هناك علاقة طويلة الاجل بين تقلبات اسعار النفط

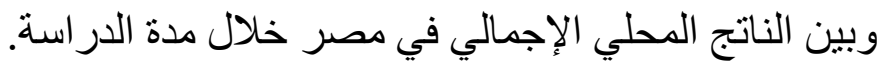

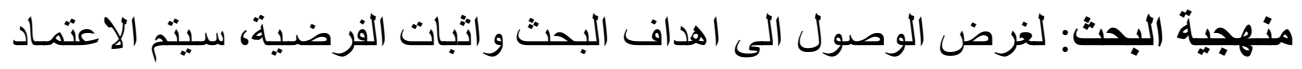

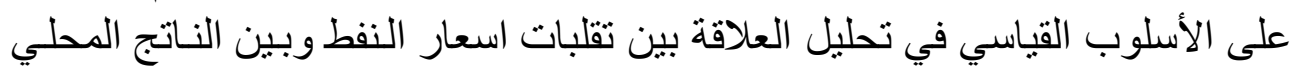

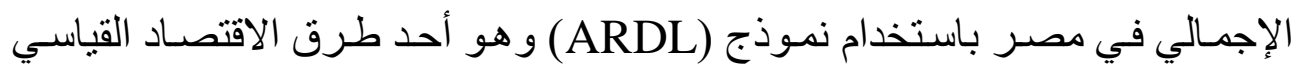

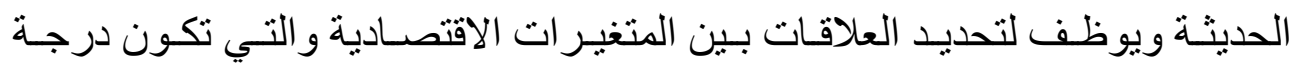
استقر ار ها مختلفة. حدود البحث: تناول البحث قياس تأثير تقلبات أسعار النفط في الناتج المحلي الإجمالي

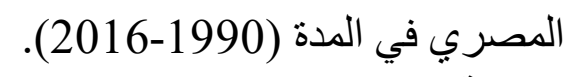

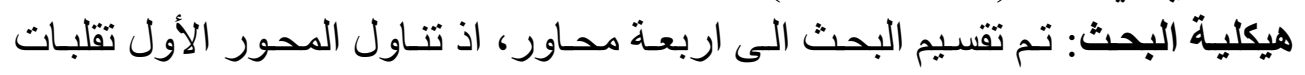

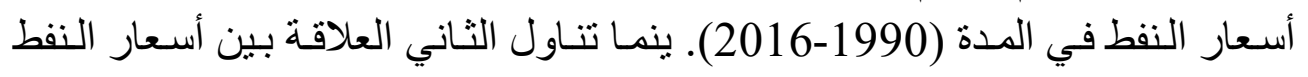

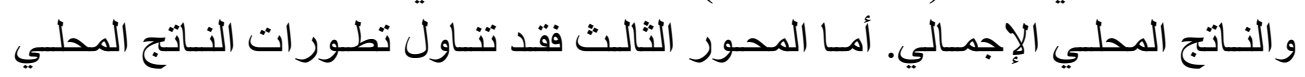

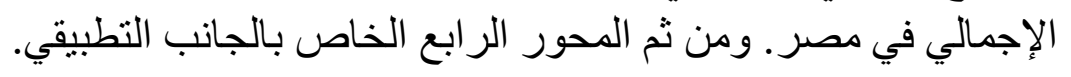

\section{المحور الأول: تقلبات أسعار النفط في المدة (1990-2016)}

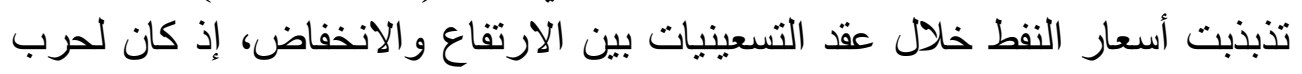

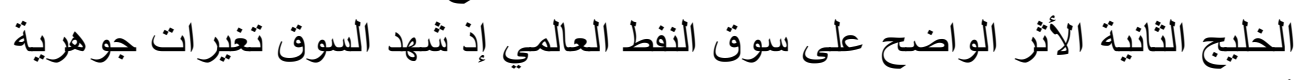

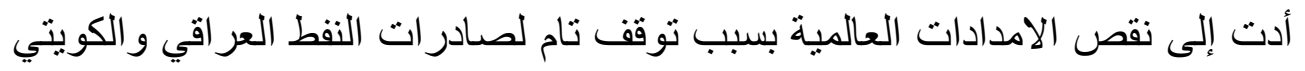

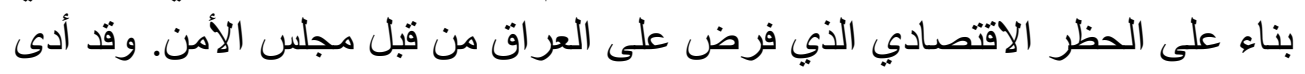

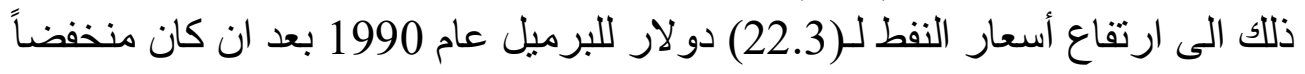

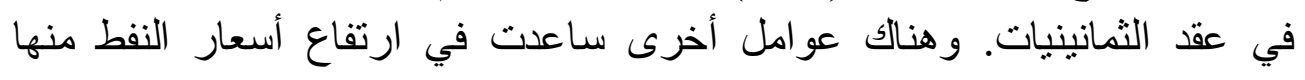

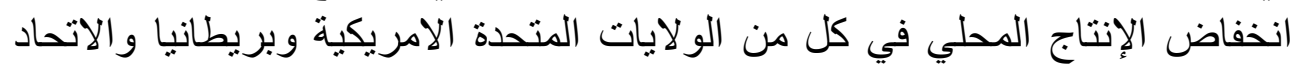

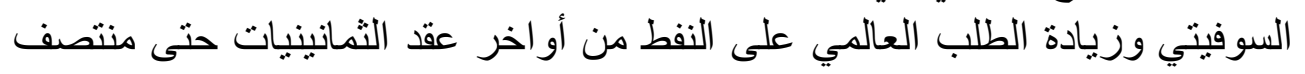

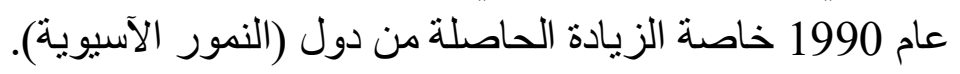

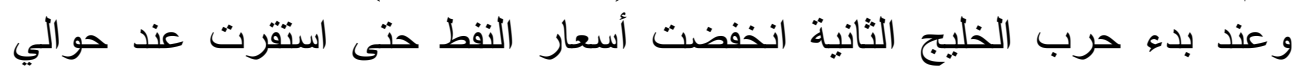

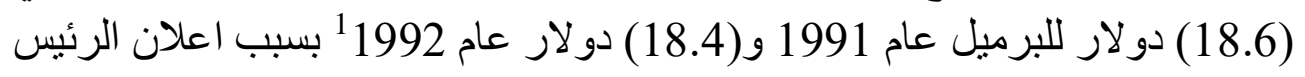

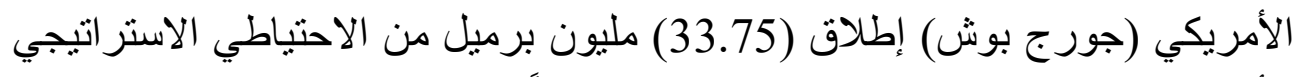

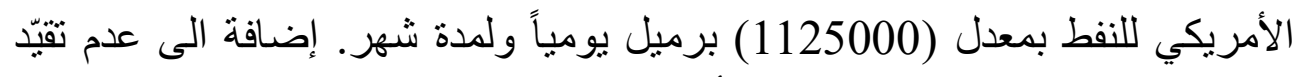

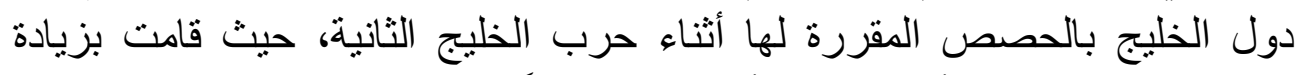

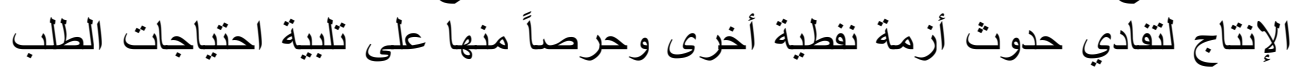


وبعد ذللك انخفض سعر برميل النفط إلى (16.3) دو لار ومن ثم الى (15.5) دو لار

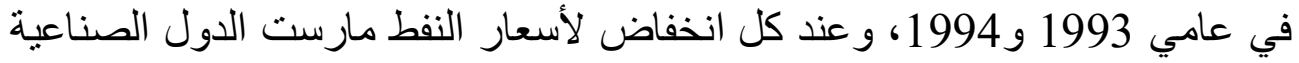

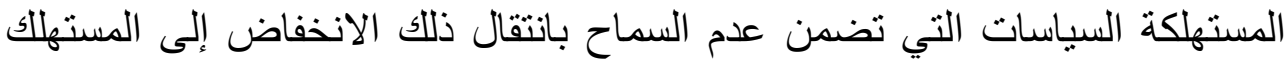

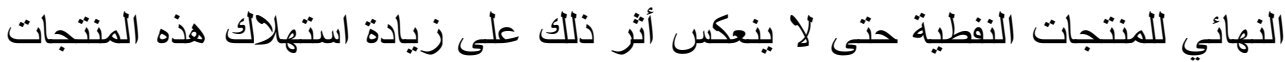

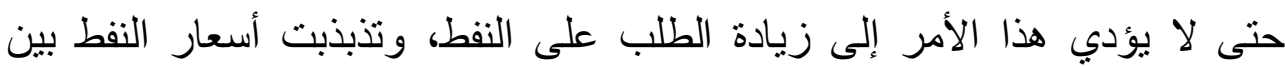

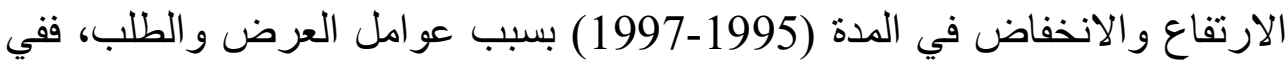

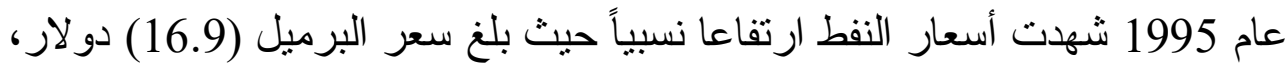

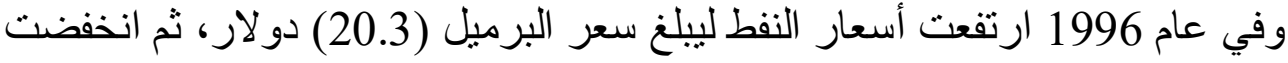

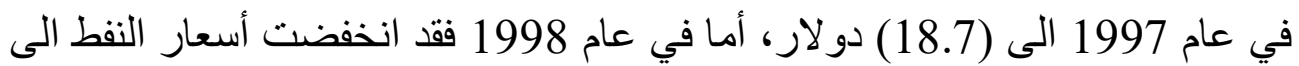

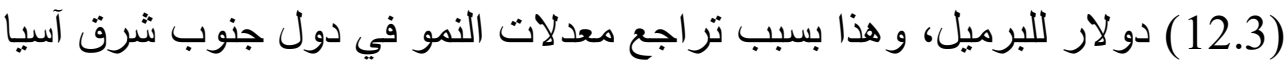

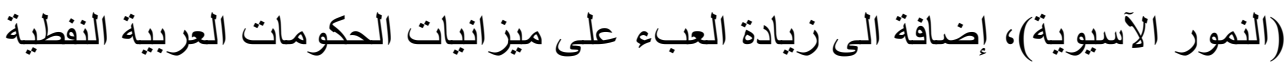

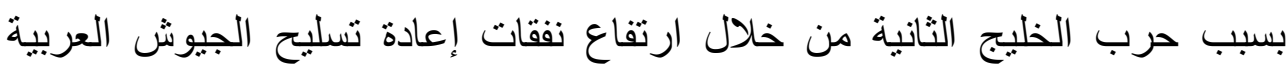

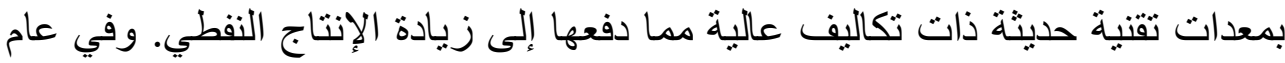

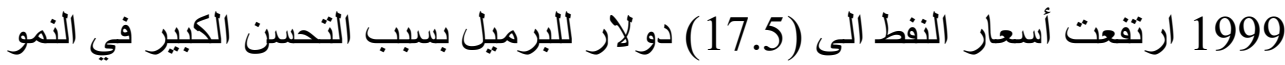

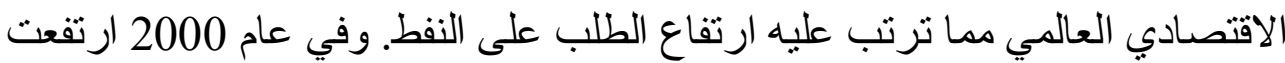

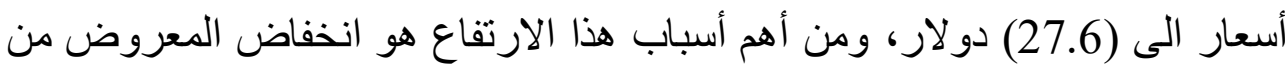

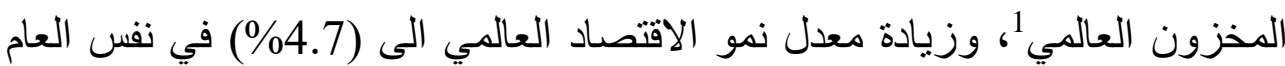

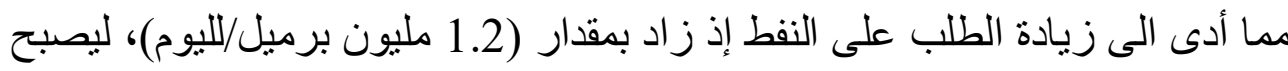
وفي (75.9 مليون برميل/لليوم).

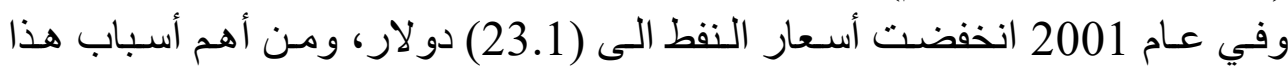

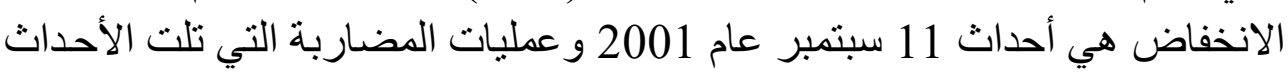

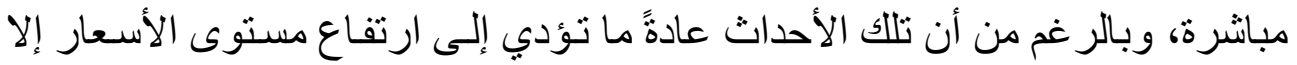

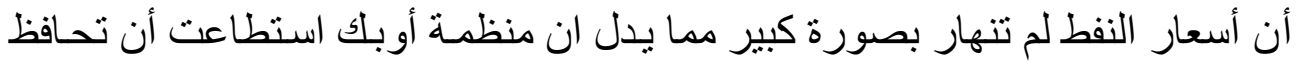
على استقرار السوق النط. وفي عام 2002 قامت منظمة أوبك بتخفيض الإنتاج بإجمالي (1.5) مليون برميل

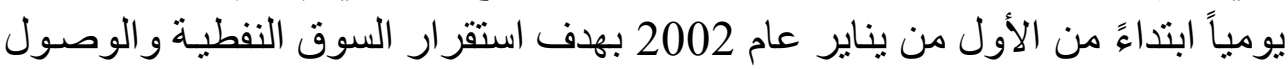

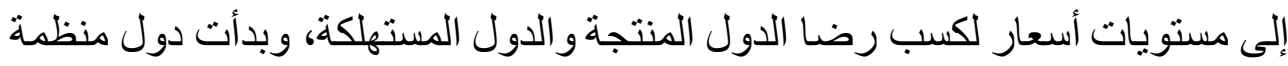

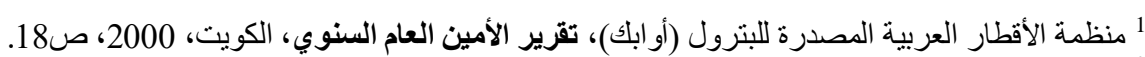

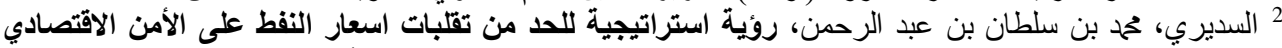

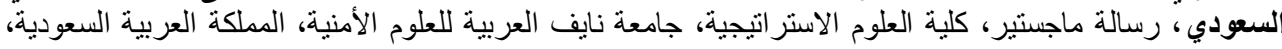

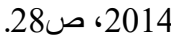
33 المزيني، عماد الدين حمحة العوامل التي اثرت على تقلبات أسعار النفط العالمية، مجلة جامعة الازهر بغزة، سلسلة 


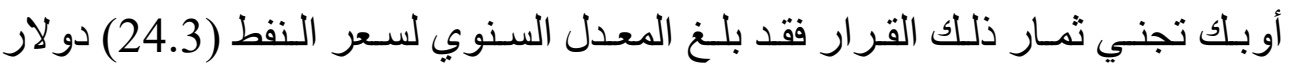

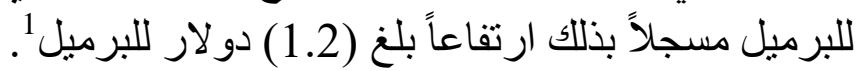

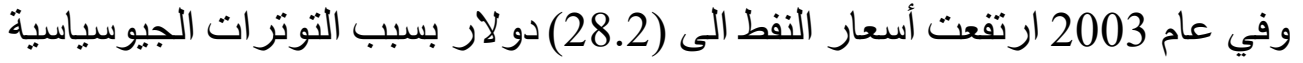

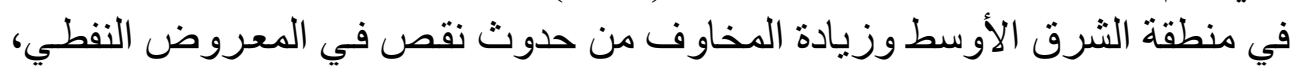

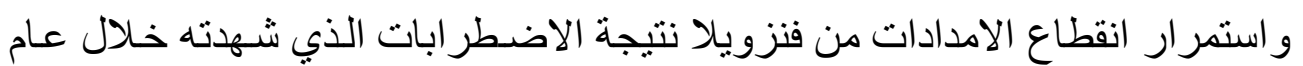

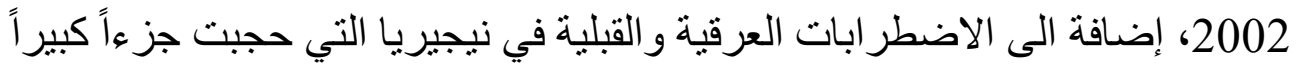

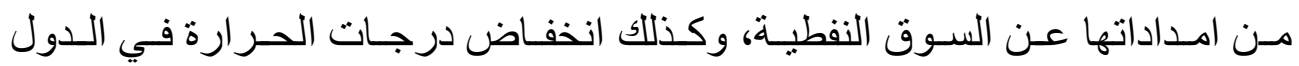

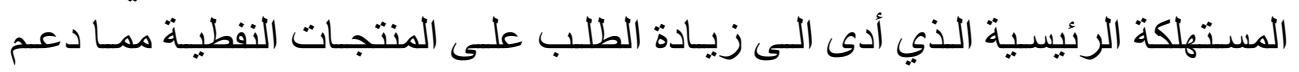

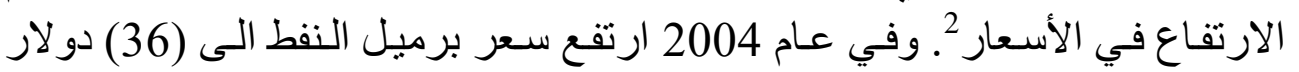

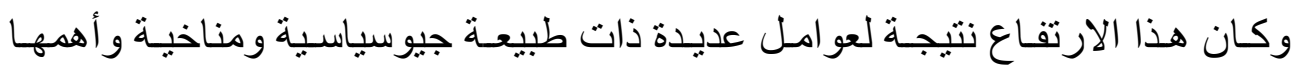

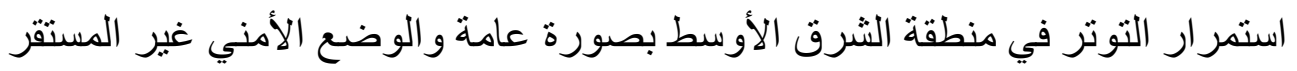

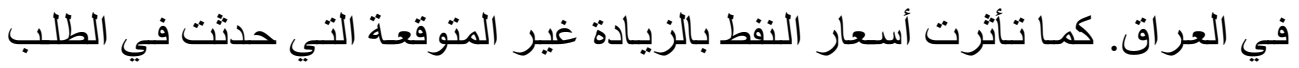

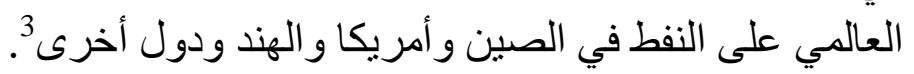

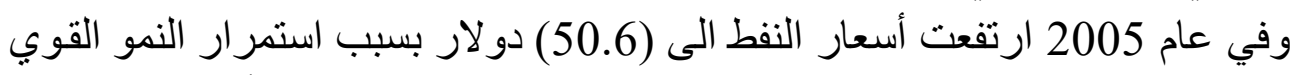

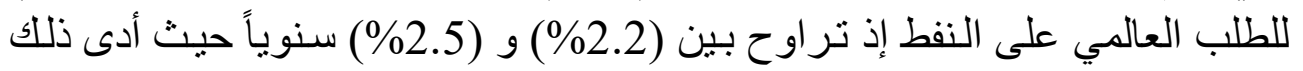

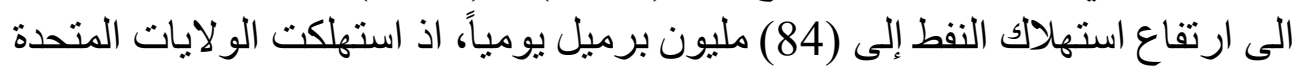

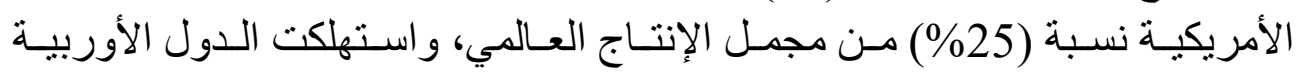

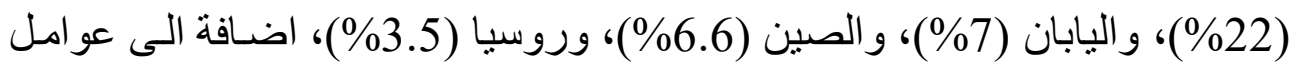

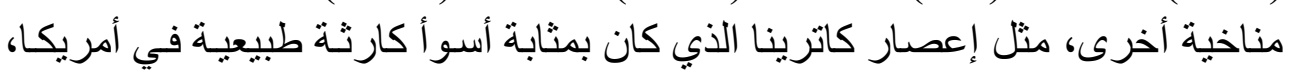

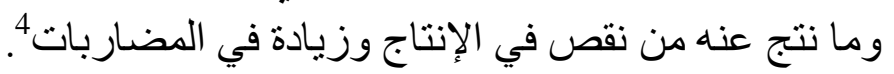

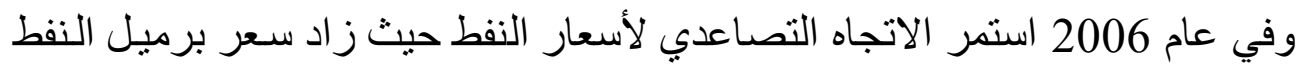

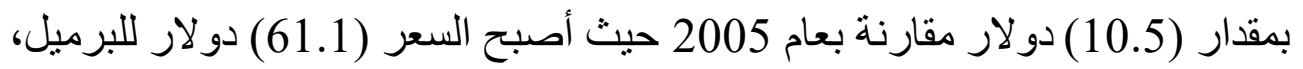

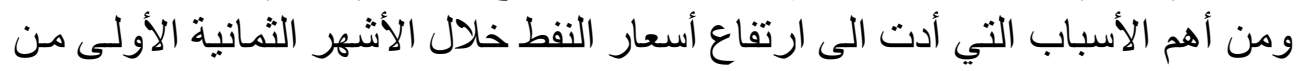

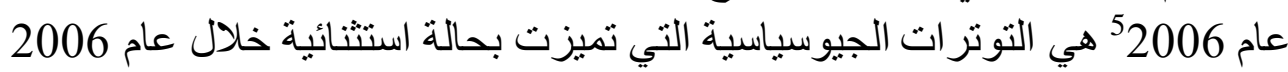

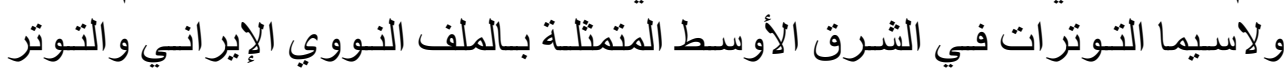
المستمر في الوضع الأمني في العر اق، وكذللك الحرب اللابنانية التي بدأت في يوم الإبر 12

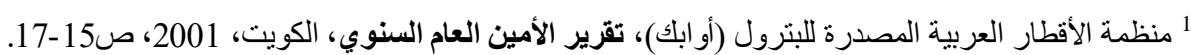

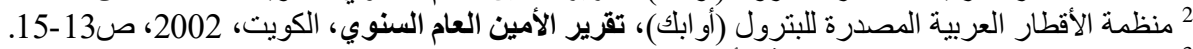

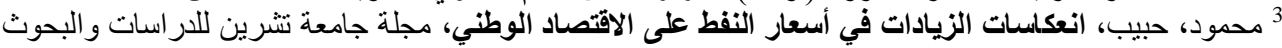

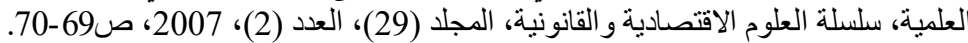

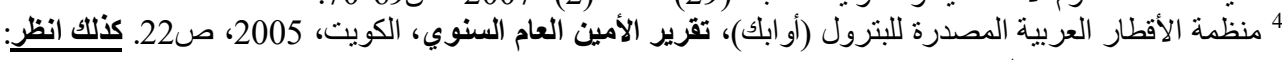

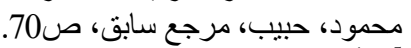

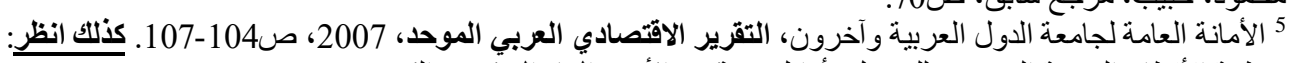

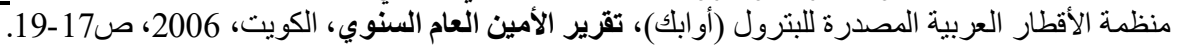


يوليو واستمر لأكثر من شهر ـ إضافة الى حدوث موجات البرد في أوربا في بداية عام

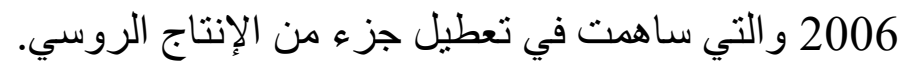

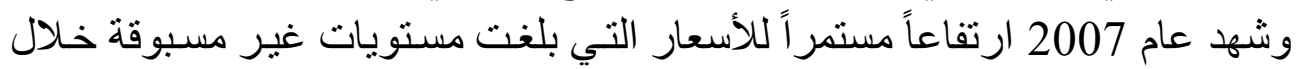

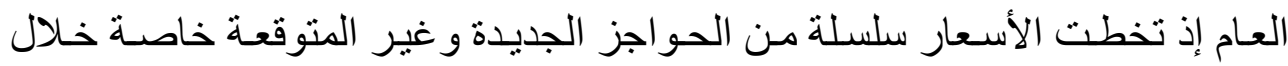

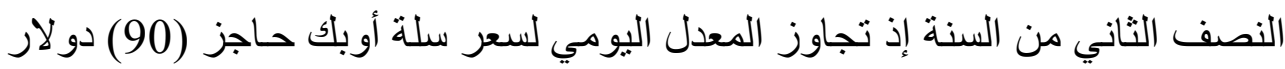

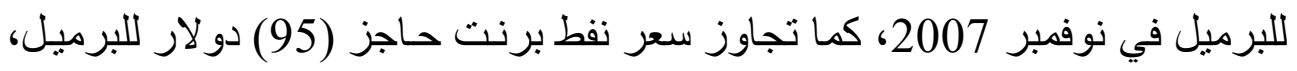

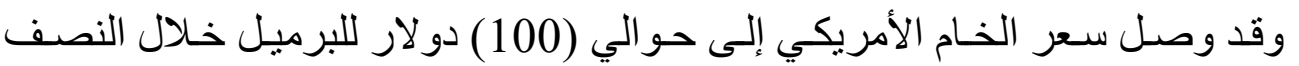

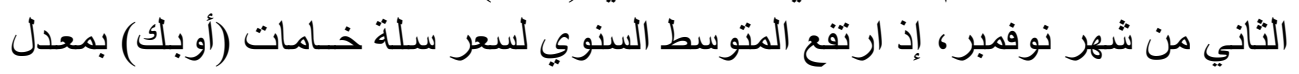

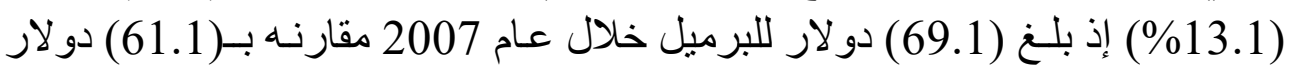

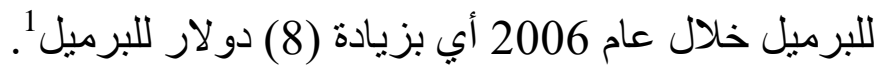

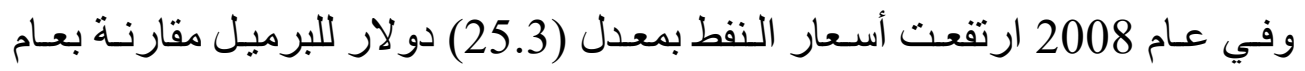

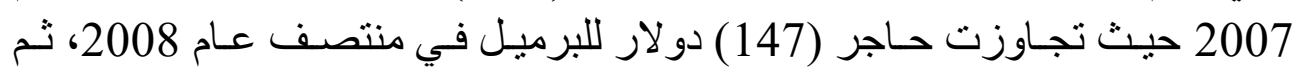

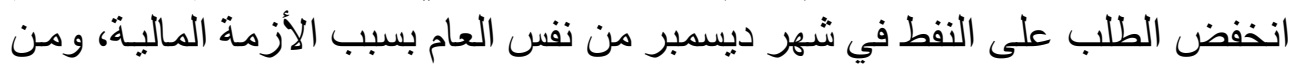

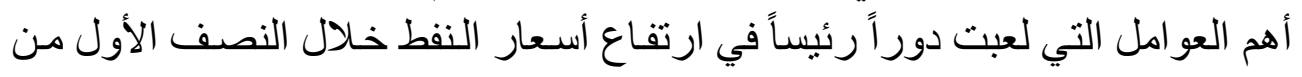

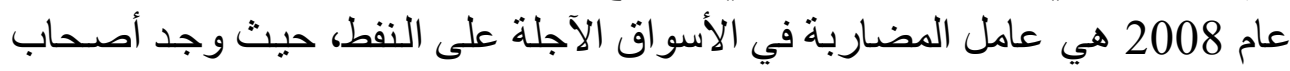

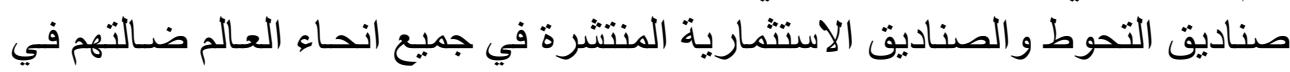

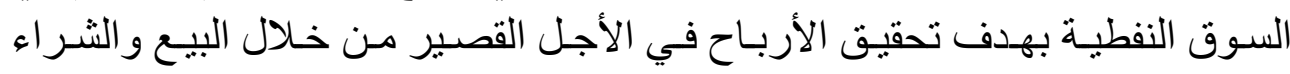

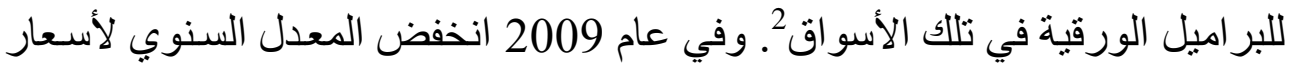

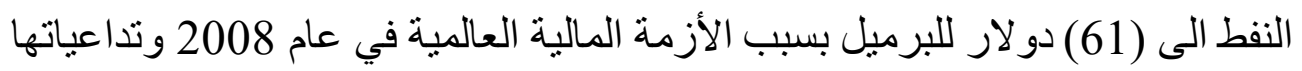

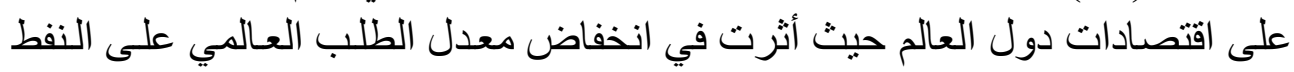

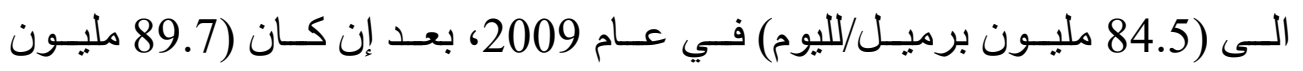

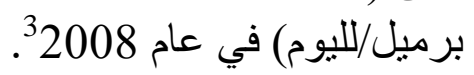

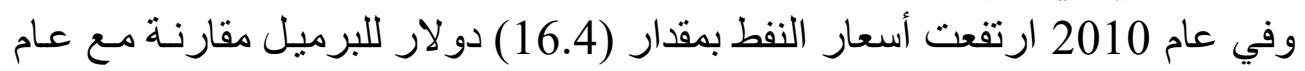

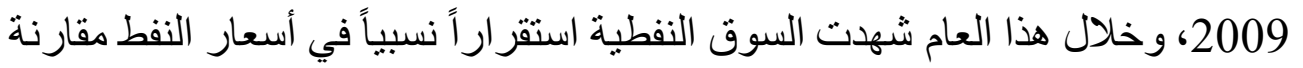

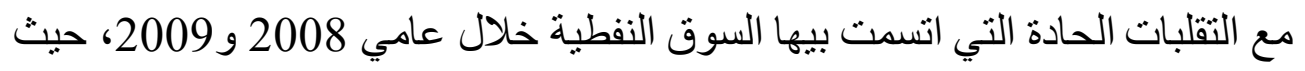

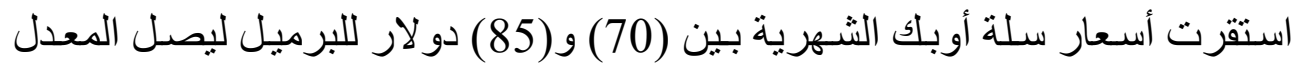

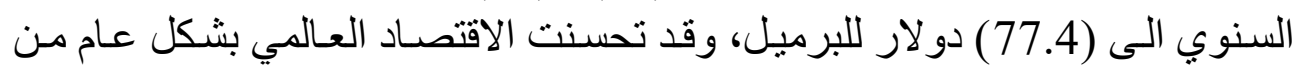
الأزمة المالية العالمية منذ منتصف عالم 2009 حيث حققت العديد من الدول الناثئة

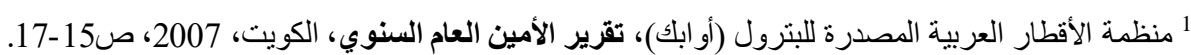

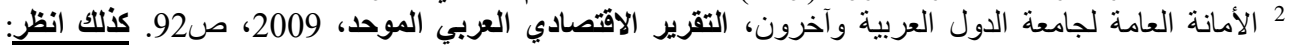

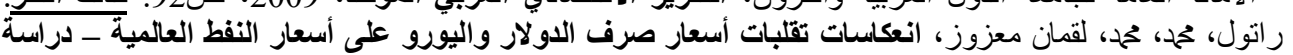

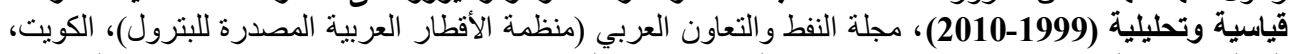

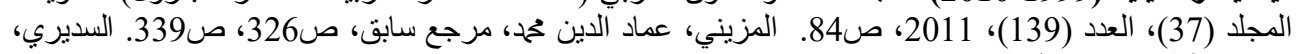

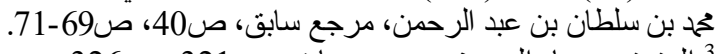

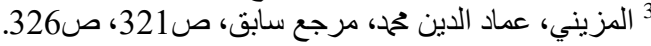


و النامية معدلات نمو اقتصادي عالية خلال العام، كذللك ارتفع الطلب على النفط بمعدل

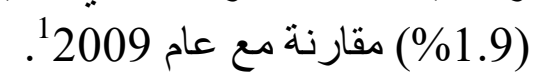

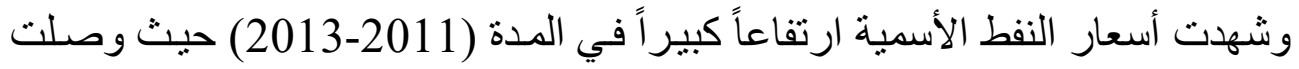

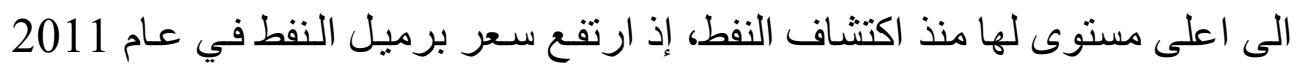

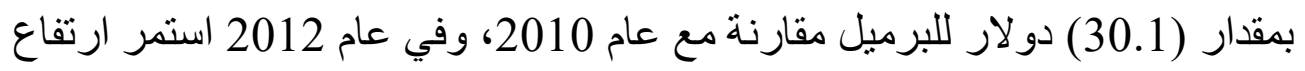

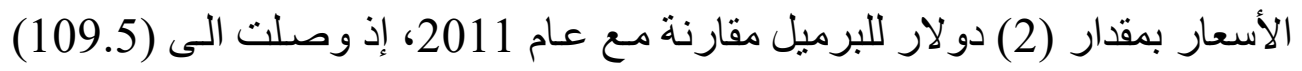

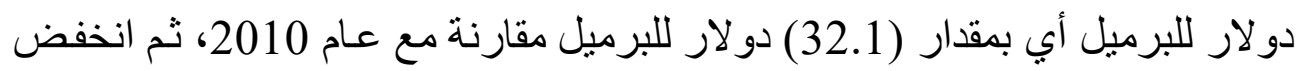

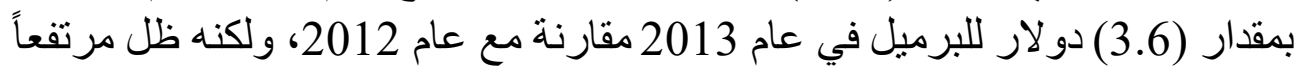

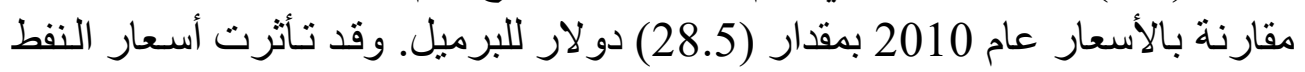

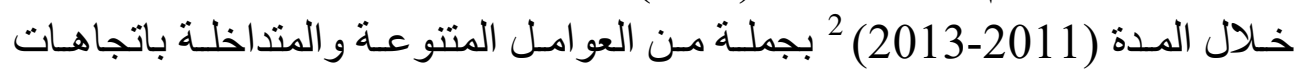

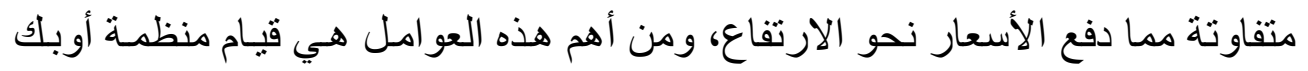

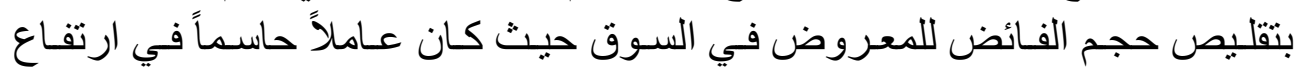

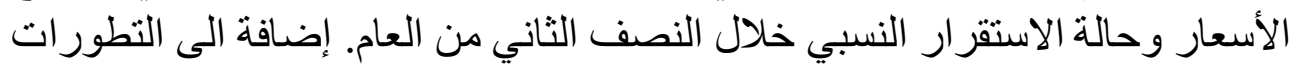

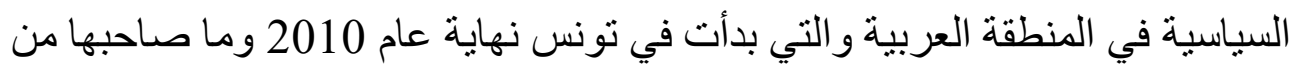

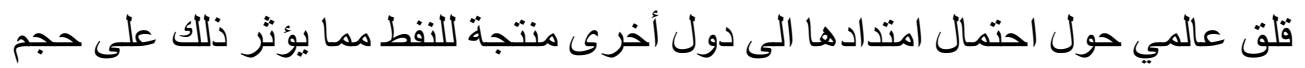
الامدادات النفطية.

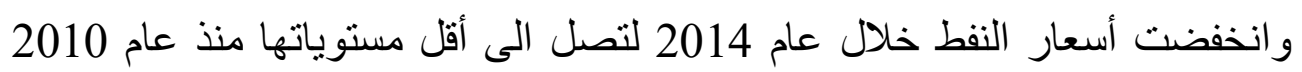

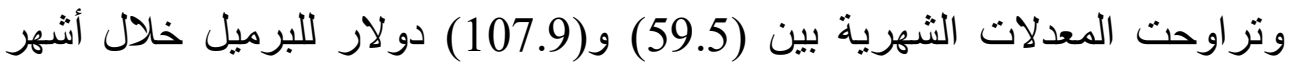

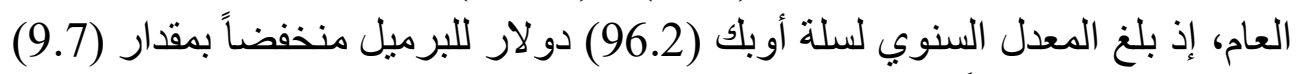

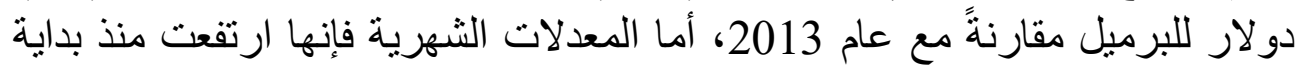

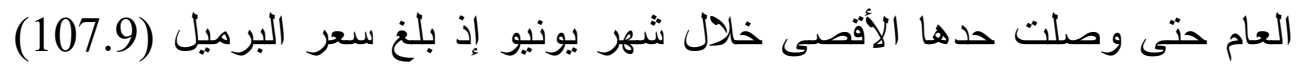

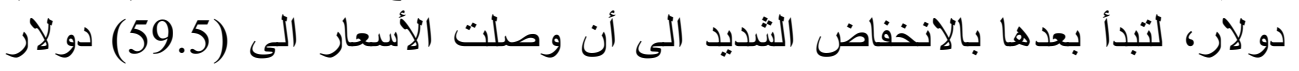

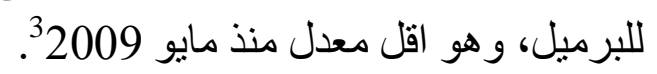

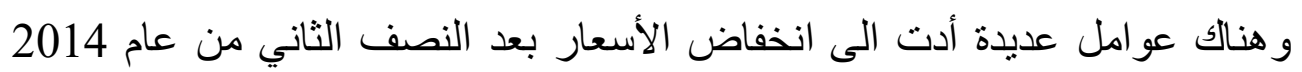

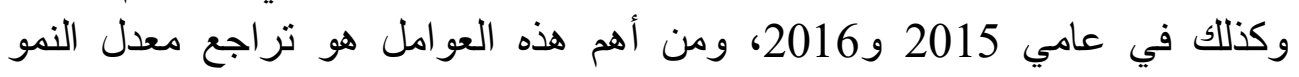

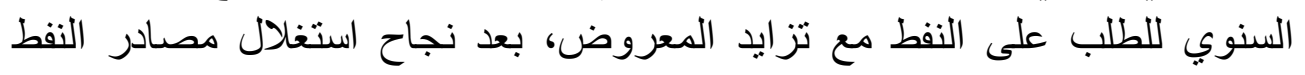

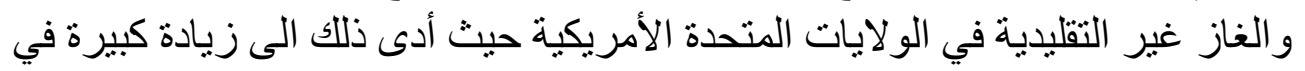

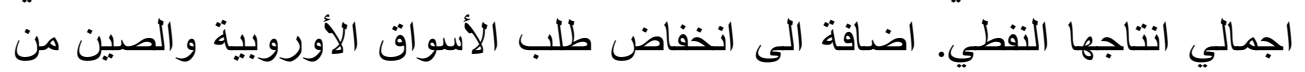

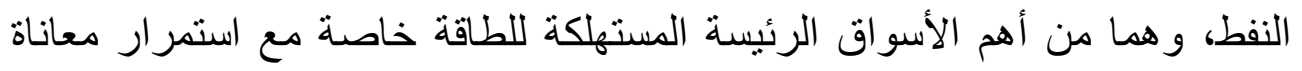

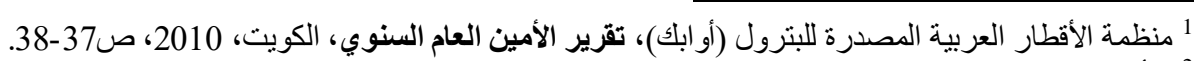

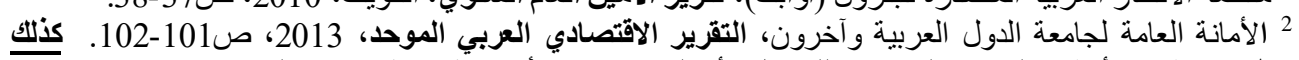

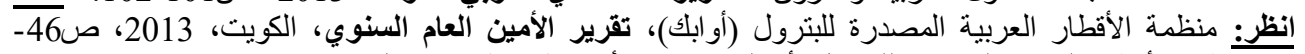

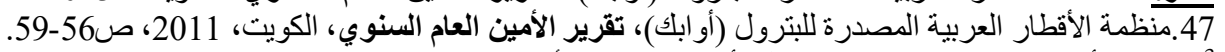

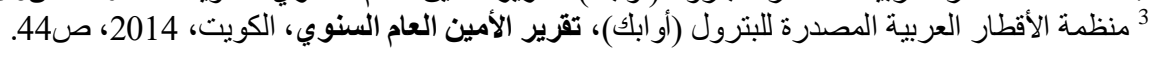


العديد من الدول الأوروبية اقتصادياً ومالياً وتز ايد المخاوف بشأن تباطؤ وتائر نمو

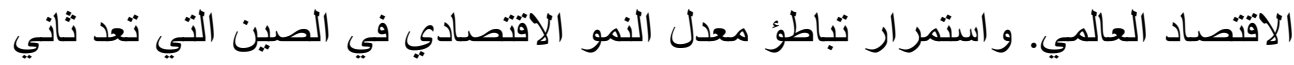

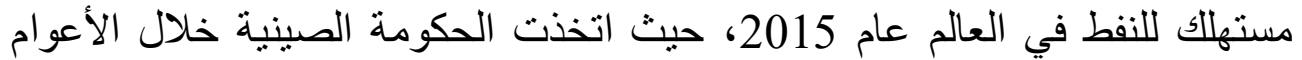

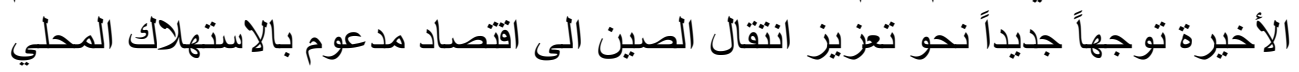

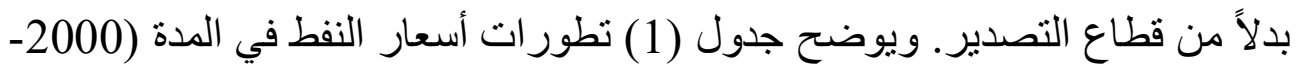

جدول (1): أسعار النفط في المدة (1990-2016)

\begin{tabular}{|c|c|c|c|c|c|}
\hline \multicolumn{6}{|c|}{ لار للبرميل } \\
\hline الحقيقي & الاسعي & السنوات & الحقيقي" & الاسمي & $ت$ \\
\hline$\tau 0$ & 2600 & & 23.9 & 202 & \\
\hline 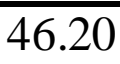 & & $200 \mathrm{~J}$ & 0.0 & & \\
\hline$\overline{0}$ & & 2006 & 9.4 & 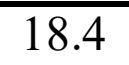 & 1007 \\
\hline 50 & & 007 & 18.1 & 6.3 & $00 ?$ \\
\hline 1.10 & 0 & 008 & 16.7 & 5.5 & 1994 \\
\hline 52.00 & 61.00 & 2009 & 19.9 & 16.9 & $\overline{1995}$ \\
\hline 65.30 & 7.40 & 2010 & 20.9 & 20.3 & 1996 \\
\hline 89.50 & 107.50 & 2011 & 20.9 & 18.7 & 1997 \\
\hline 90.10 & 9.50 & 2012 & 14.5 & 12.3 & 1998 \\
\hline 86.10 & 105.90 & 2013 & 20.80 & 17.5 & 1999 \\
\hline 77.10 & 96.20 & 2014 & 27.60 & 27.60 & 2000 \\
\hline 39.30 & 49.50 & 2015 & 22.70 & 23.10 & 2001 \\
\hline 32.0 & 40.7 & 2016 & 23.50 & 24.30 & 2002 \\
\hline & & & 26.80 & 8.20 & 2003 \\
\hline
\end{tabular}

الجدول من اعداد الباحث بالاعتماد علىى:

1. الأمانة العامة لجامعة الدول العربية وآخرون، التقريز الاقتصادي العربي الموحد، للأعوام

.(2018-2000)

2. منظمة الأقطار العربية المصدرة للنفط (أو ابك)، التقرير الإحصائي السنوي، للأعوام (2005-

. (2016 


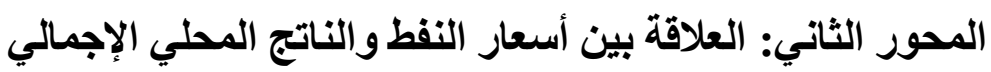

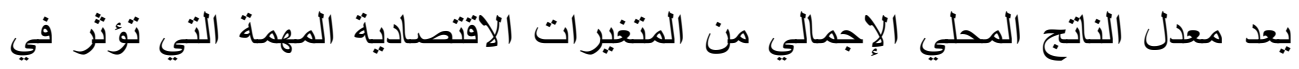

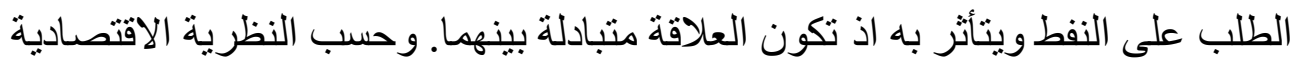

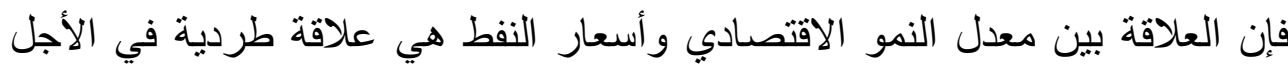

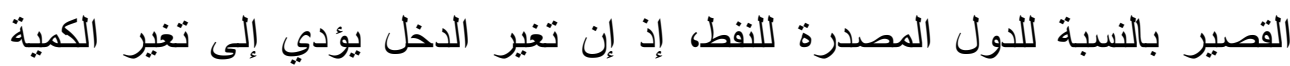

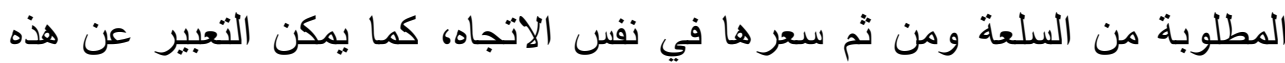

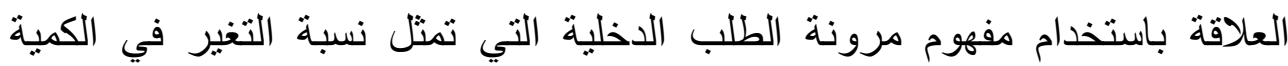

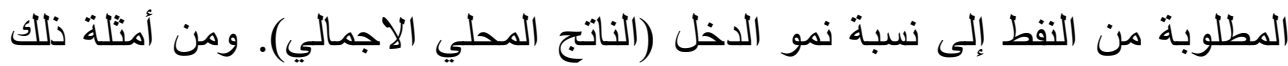

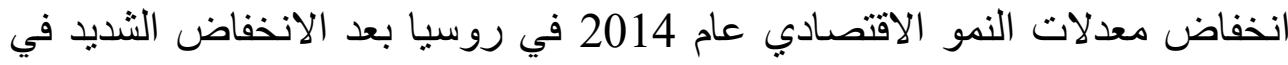

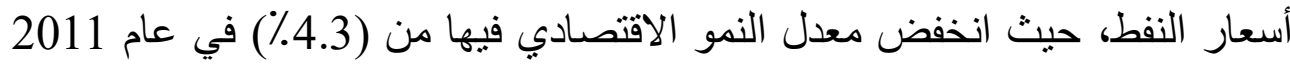

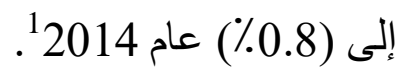

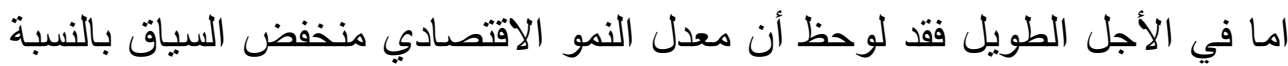

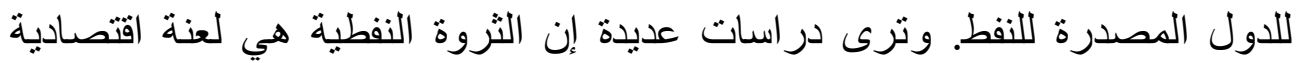
تصيب هذه الدول، إذ كلما زادت الثروة النفطية التي تستخرجها الدول النفطية كلما أدى ذللك إلى تدني معدلات النمول النمو الاقتصادي.

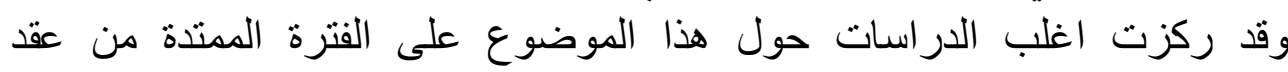

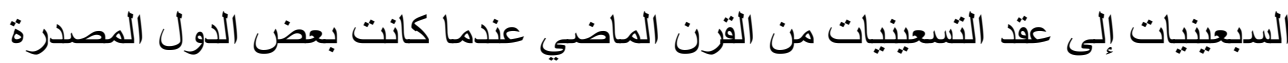

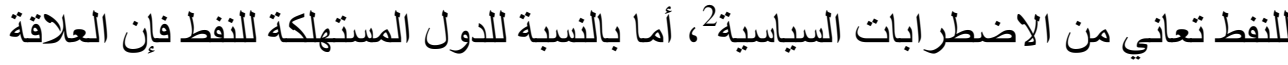

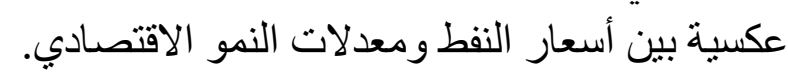

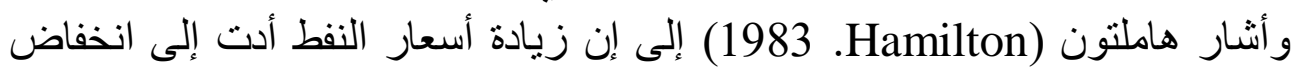

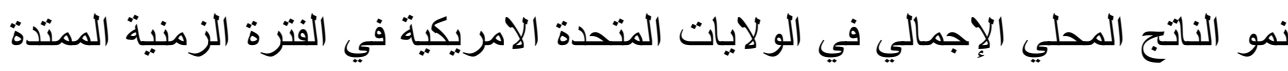

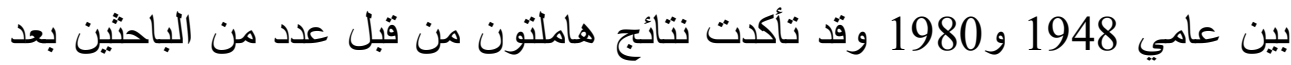

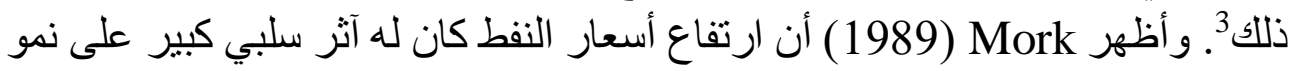

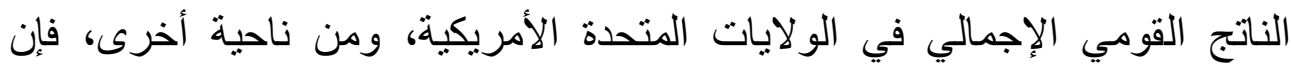

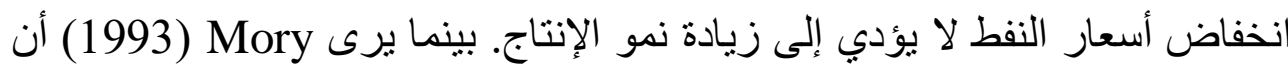

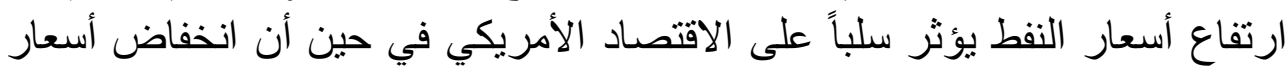

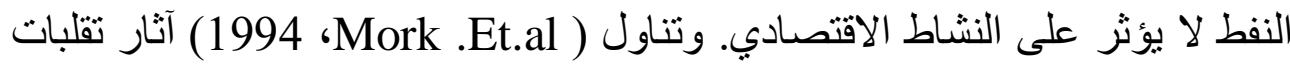

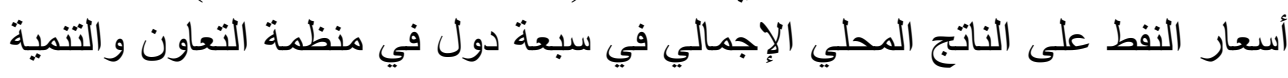

${ }^{1}$ Martin Russell, The Russian Economy-Will Russia ever catch up?, EPRS/European Parliamentary Research Service, March 2015, p.20.

2 روس، مايكل، نقمة النفط - كيف تؤثر الثروة النفطية على نمو الأمم، ترجمة: ححمد هيثم نشواني، الطبعة الأولى،

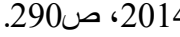

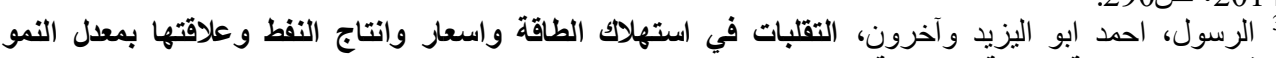

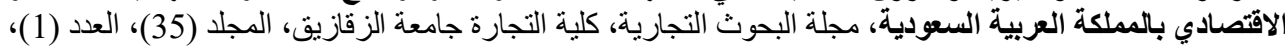


وتوصلت الى أن تأثير زيادة أسعار النفط على الناتج المحلي الإجمالي سلبي في جميع

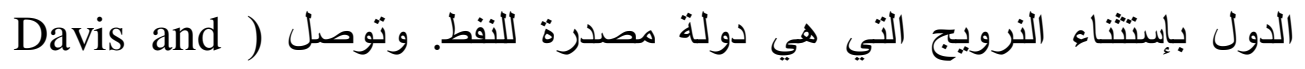
2001 ، Haltiwanger الصدمات النقدية على معدل النمو الاقتصادي!.

وقد تناول Dotsey and Reid (1992) في سلسلة زمنية فصلية للو لايات المتحدة

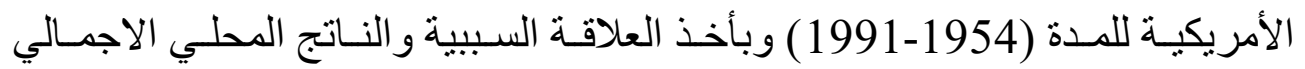

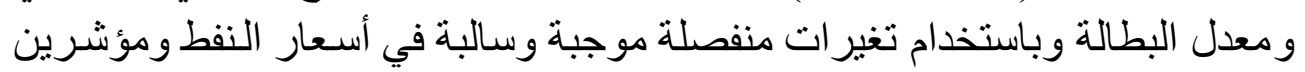

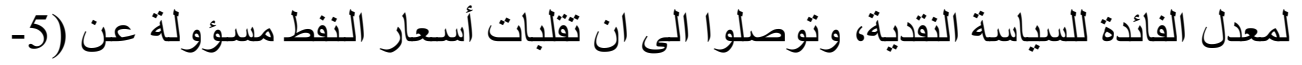

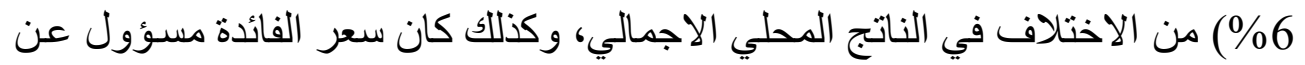

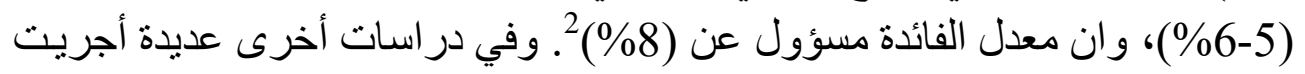

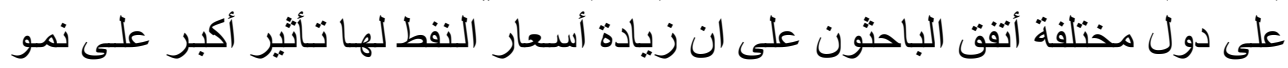
الناتج المحلي الإجمالي الحقيقي في الدول البالئ الدصدرة للنفط.

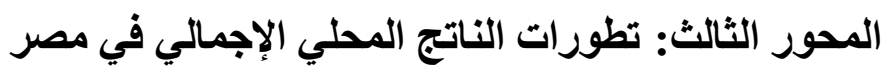

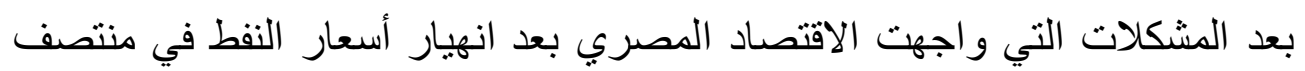

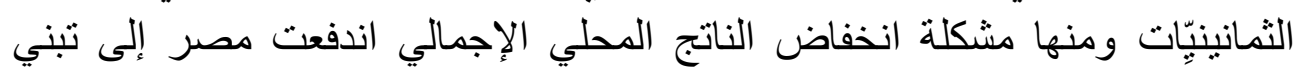

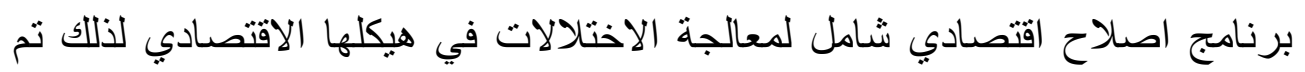

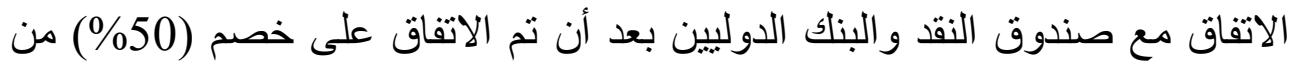

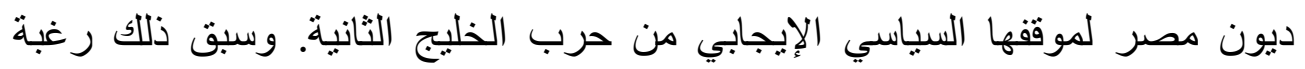

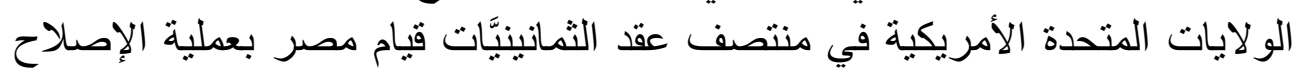

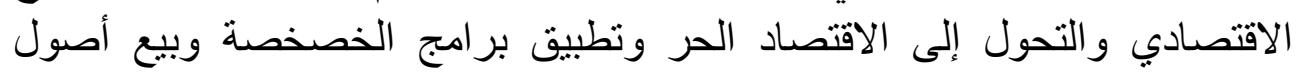

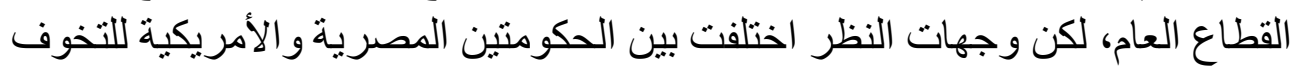

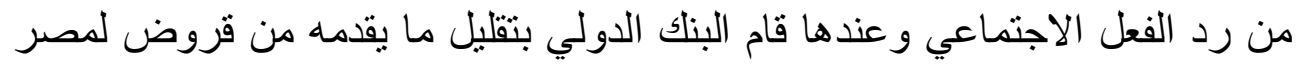

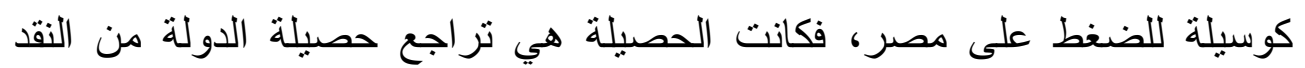

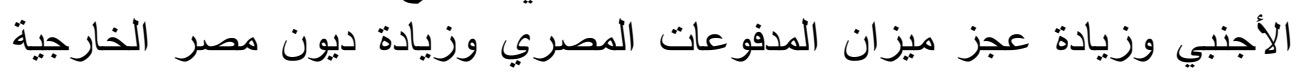

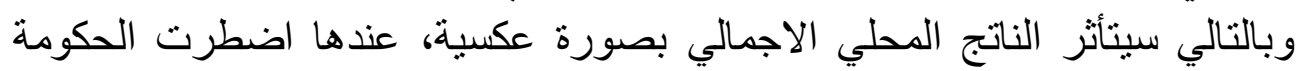

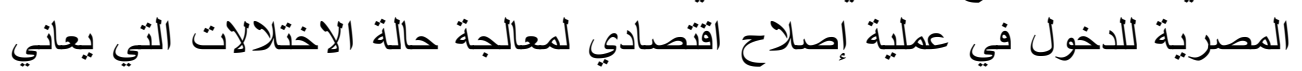
منها اقتصاد هاج3.

${ }^{1}$ Alotaibi, Bader, Oil Price Fluctuations and the Gulf Cooperation Council (Gcc) Countries 1960-2004, PH.D thesis, Southern Illinois University Carbondale, May 2006, p.15.

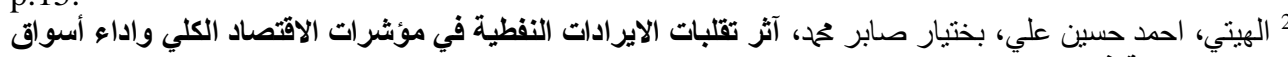

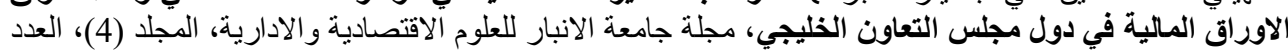

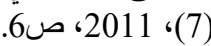

"3 قاسم، منى، الإصلاح الاقتصادي في مصر ، مرجع سابق، ص222 


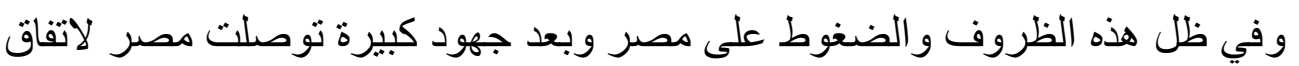

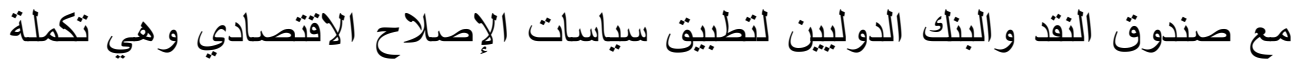

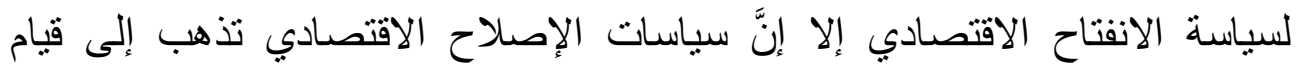

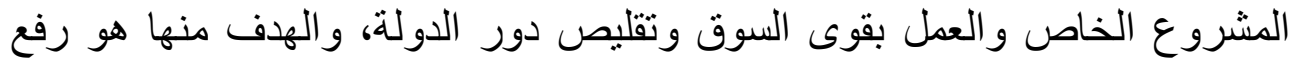
معدلات النمو الاقتصادي المصري وتحسين مستوى المعيشة للسكان والارتقاء

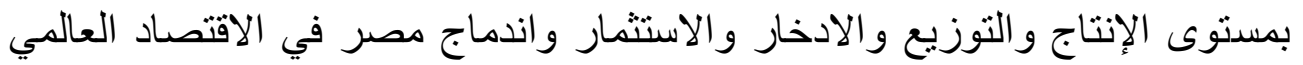
بهيكل اقتصادي منين أ.

ومن هذه الإجراءات المقترحةّ، رفع أسعار الخدمات العامة التي تقدمها الدولة (الوقود، الكهرباء، المو اصلات) وتحميلها إلى المستفيد مباشرة بأسعار ها الحقيقية، كذللك تشجيع القطاع الخاص على الاستثمار في جميع القطاعات بما في ذلك القطاع

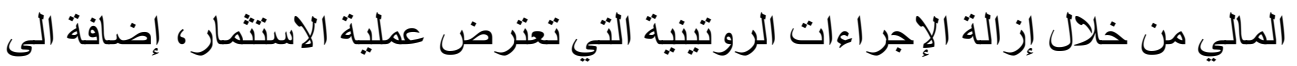

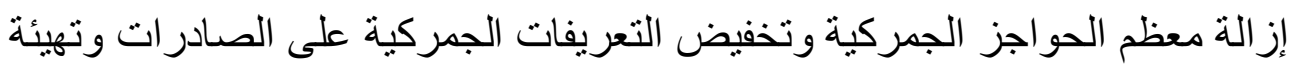

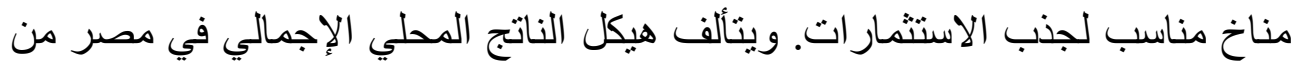
قطاع الإنتاج السلعي وقطاع الخدمات الإنتاجية وقطاع الخدمات الاجتماعية، وكما

1. قطاع الإنتاج السلعي. ويتكون من القطاع الزر اعي والصناعات الاستخر اجية بلي:

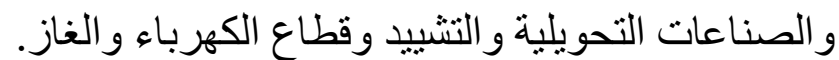

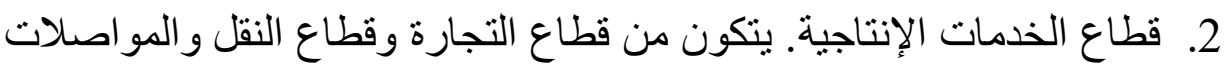

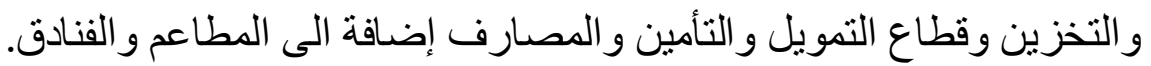
3. قطاع الخدمات الاجتماعية. يتكون من قطاع الإسكان و الخدمات الحكومية.

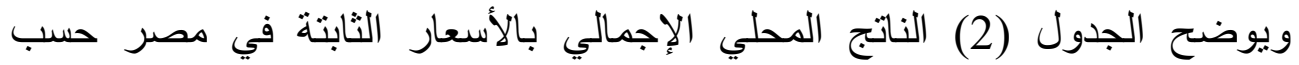
القطاعات للمدة (1990-2016). حيث شهد الناتج المحلي الإجمالي مساراً تصاعدياً من (87.39) مليار دو لار في عام 1990 الى (260.80) مليار دو لار في عام 2016

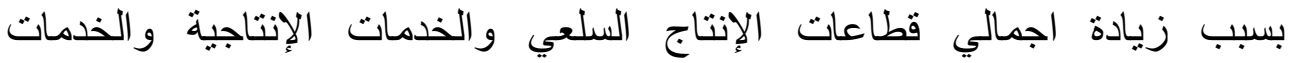

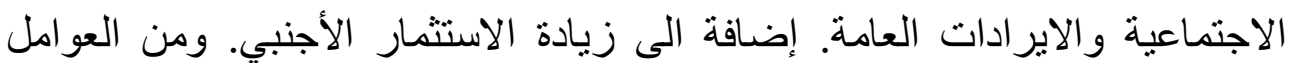

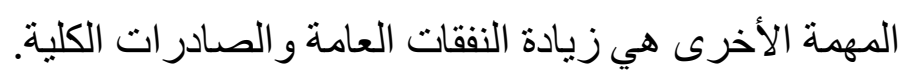

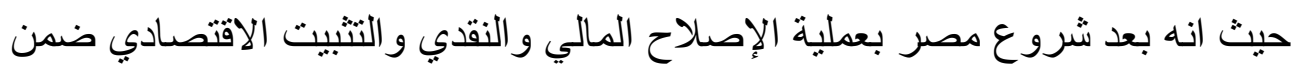
برنامج الإصلاح الاقتصادي اتخذت الحكومة المصرية في عام 1991 سياسات

1 غيدان، جلبل كامل، قياس أثر برامج الإصلاح الاقتصادي على الفجوة الغذائية في الوطن العربي (مصر، الأردن،

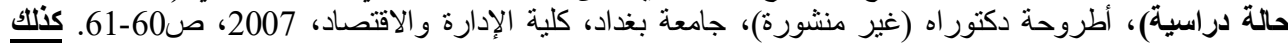
النظلِ: ابو الفضل، فتحي واخرون، دور الدولة والمؤسسات في ظل العولمة، الهيئة الدصرية العامة للكتاب، الطبعة

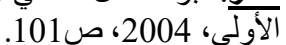
2ُ شمس الدين، أثنرف، تقييم برنامج الخصخصة الاقتصادية والاجتماعية لغرب آسيا، الأمم الدتحدة، نيويورك، 1995، 
اقتصادية انكمانشية تتمثل في تقليص الإنفاق العام وتوسيع الإير ادات العامة لعلاج

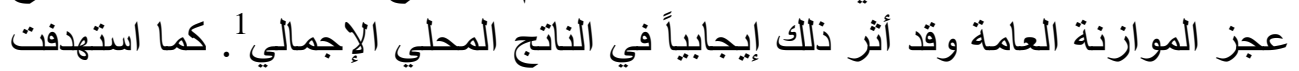

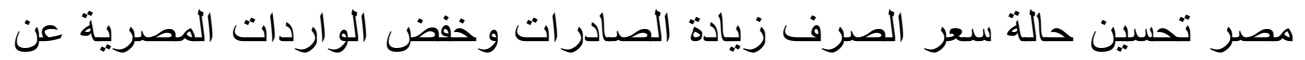

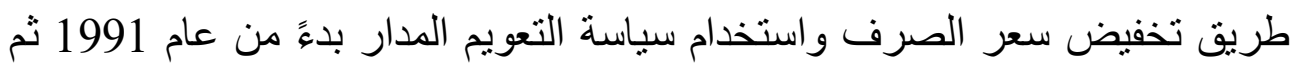

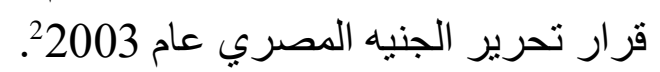

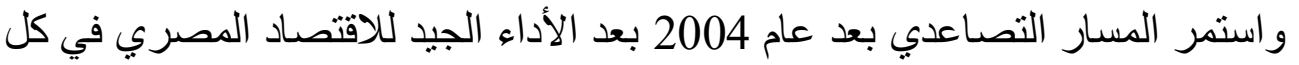

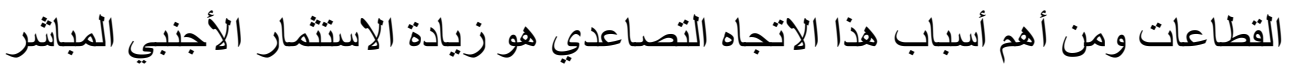

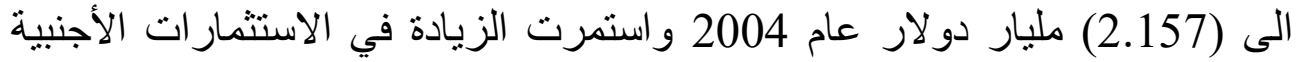

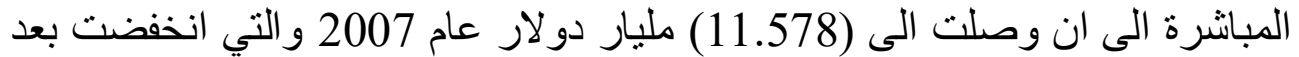

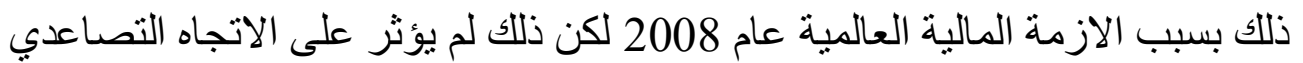

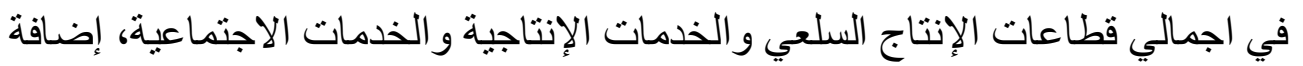

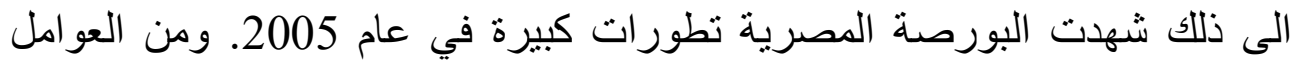

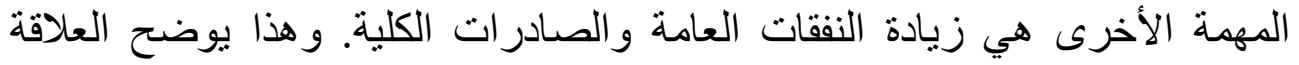

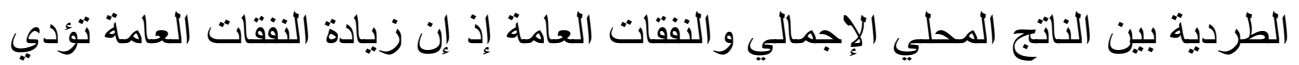

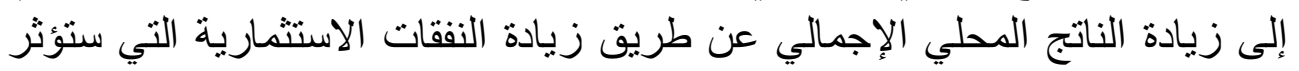
ايجابياً على الصادر ات المصرية الإحلي الناتج المحلي الإجمالي. زيادي.

${ }^{1}$ IMF. Survey, A publication of the international monetary fund, October 28, 1996, p.354. وللمزيد من التفاصيل:

1- korayem, Karima, Adjustment and Reform policies Egypt, Economic and social council , economic and social commission for western Asia, October, 1993, p.16.

2- The World Bank, Trends in economic developing countries, World Bank, Washington D.C, 1994, p.164.

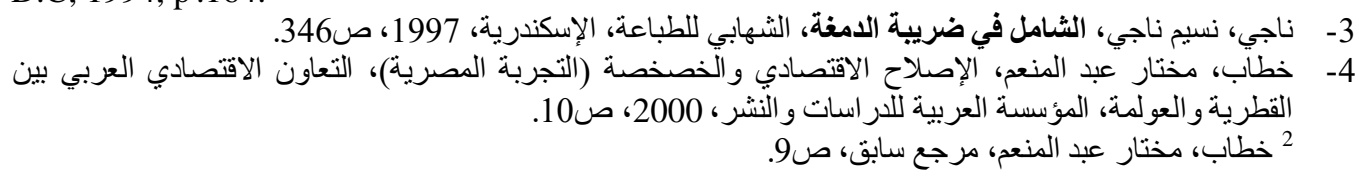


جدول (2): الناتج المحلي الإجمالي في مصر للمدة (1990-2016)

\begin{tabular}{|c|c|c|c|}
\hline الإحمالي & السنة & الاجمالي & السنة \\
\hline 155.27 & 2004 & 87.39 & 1990 \\
\hline 162.21 & 2005 & 88.38 & 1991 \\
\hline 173.31 & 2006 & 92.33 & 1992 \\
\hline 185.60 & 2007 & 95.01 & 1993 \\
\hline 198.88 & 2008 & 98.78 & 1994 \\
\hline 208.17 & 2009 & 103.37 & $\overline{1995}$ \\
\hline 218.89 & 2010 & \begin{tabular}{|l|}
108.53 \\
\end{tabular} & 1996 \\
\hline 222.75 & 2011 & 114.49 & 1997 \\
\hline 227.71 & 2012 & 120.87 & 1998 \\
\hline 232.69 & 2013 & 128.19 & 1999 \\
\hline 239.47 & 2014 & 136.35 & 2000 \\
\hline 249.94 & 2015 & 141.17 & 2001 \\
\hline \multirow[t]{2}{*}{260.80} & 2016 & 144.55 & 2002 \\
\hline & & 149.16 & 2003 \\
\hline
\end{tabular}

الجدول من اعداد الباحث بالاعتماد على: 1. تقارير البنك الدولي للأعوام (2010-2017).

2. الأمانة العامة لجامعة الدول العربية و آخرون، التقرير الاقتصادي العربي الموحد، للأعوام (2000-2017).

\section{المحور الرابع: الجانب التطبيقي}

يعد نموذج (Autoregressive Distributed Lag) أحد طرق الاقتصاد القياسي الحديثة ويوظف لتحديد العلاقات بين المتغيرات الاقتصادية والتي تكون درجة

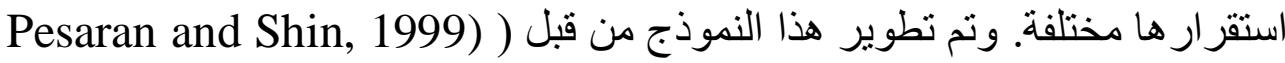
(and (Pesaran et al. 2001

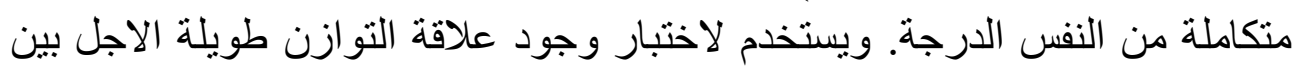

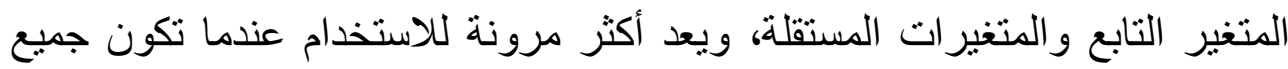




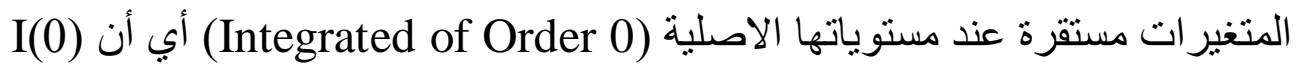

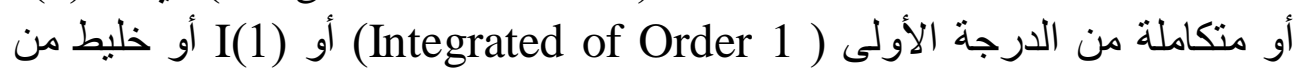

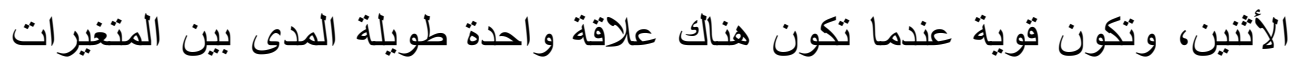

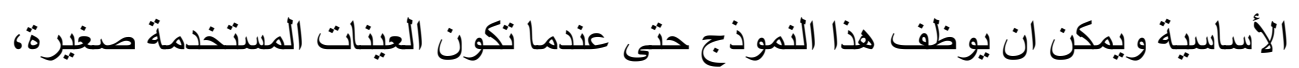

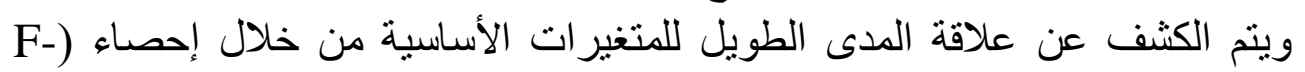

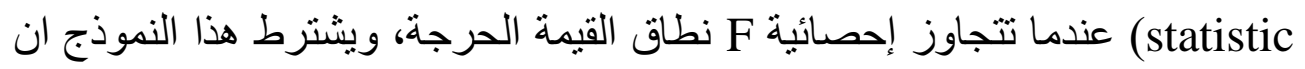

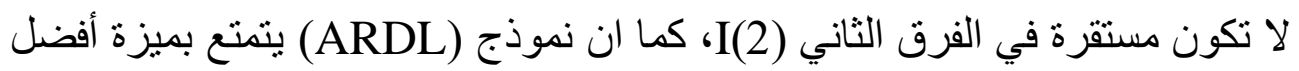

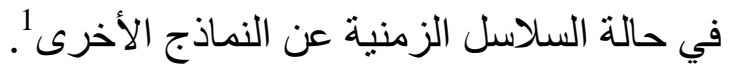

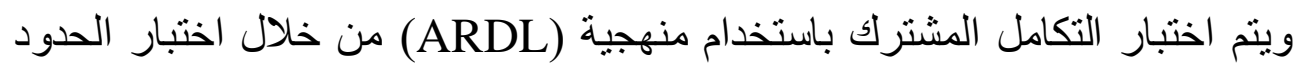
(المطور من قبل (Bound Test)

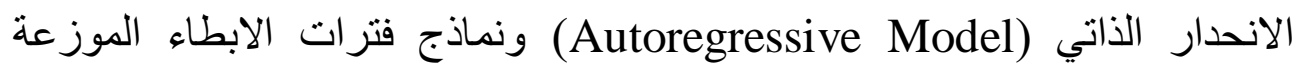

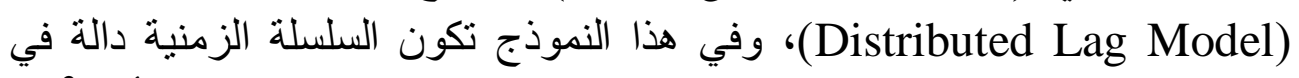

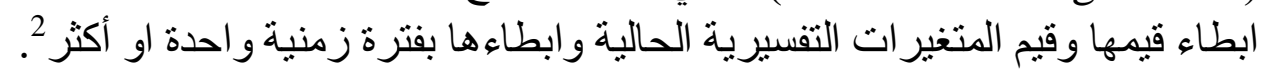

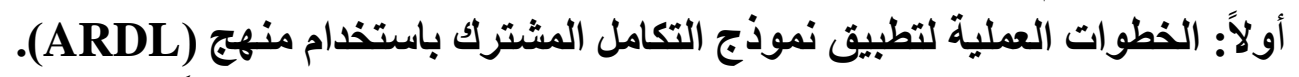

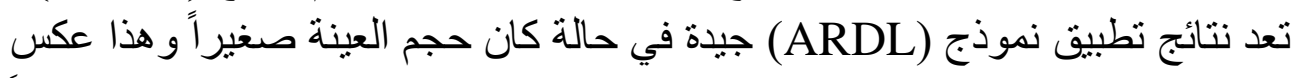

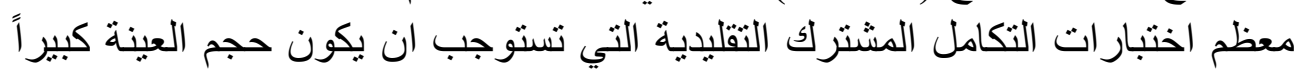

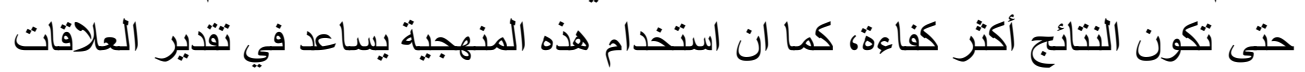

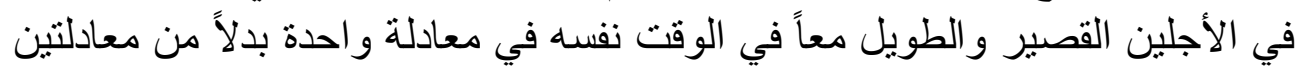

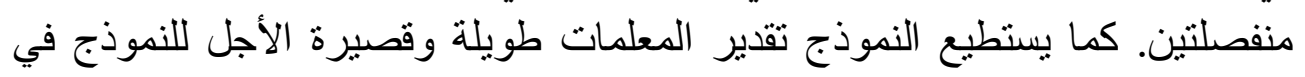

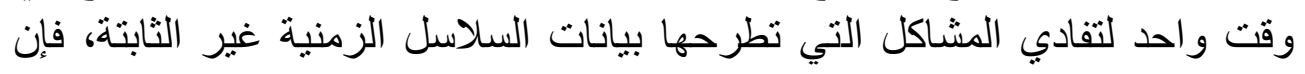

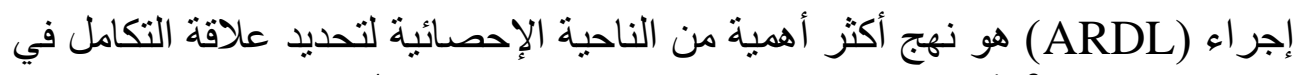

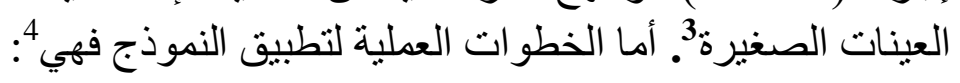

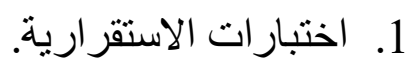

2. اختيار فترة الابطاء المتلى للفروق الأولى للمتغيرات في نموذج تصحيح

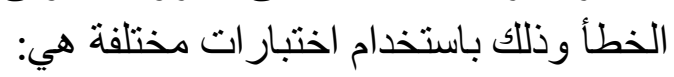

اختبار خطأ التنبؤ النهائي (Final prediction error :FE).

1 Nkoro, Emeka ,Aham Kelvin Uko, Autoregressive Distributed Lag (ARDL) cointegration technique: application and interpretation, Journal of Statistical and Econometric Methods, vol.5, no.4, 2016, P.68.

2 حواس، امين، فاطمة الزهراء زرواط، واردات السمع الرأسمالي والنمو الاقتصادي في الصين :منهجية ARDL

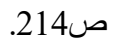

${ }^{3}$ Hamuda, Abdulbaset M., et.al, ARL investment model of Tunisia, Theoretical and Applied Economics, Volume XX (2013), No. 2(579), p.62.

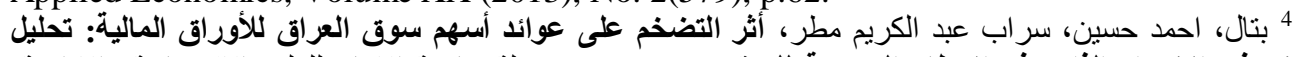

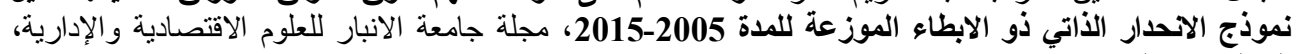

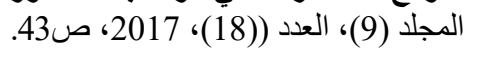




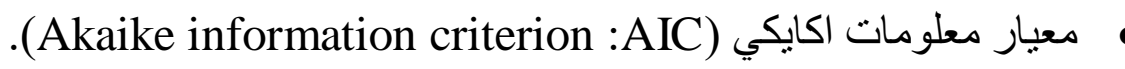

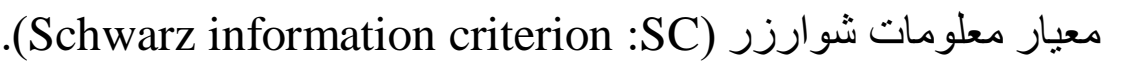

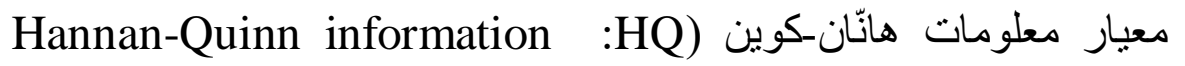
.criterion

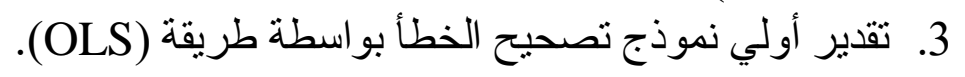

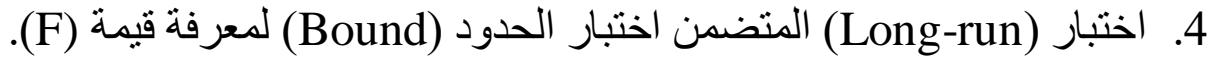

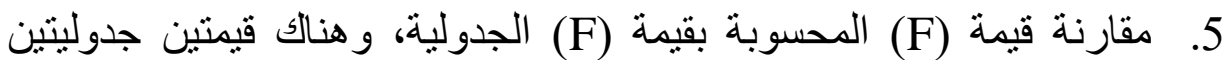

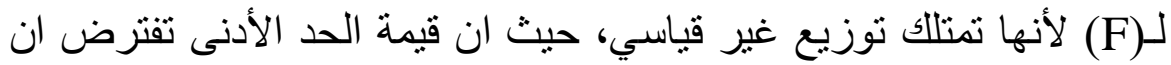

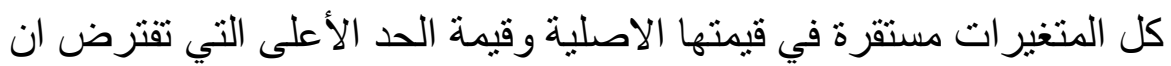
المتغير ات مستقرة في الفرق الأول، وحسب الحالات التالية:

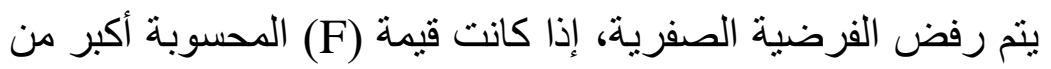
قيمة الحد الأعلى لقيمة (F) الجدولية، مما يعني وجود النية علاقة تكامل مشترك بين المتغيرات.

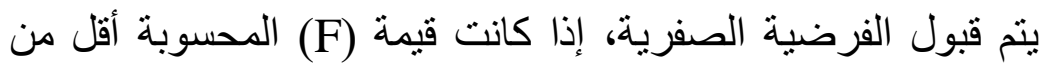

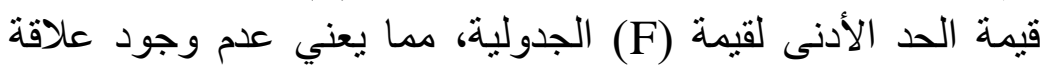

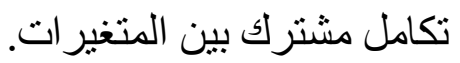

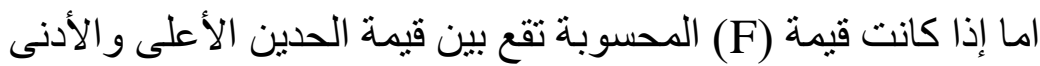

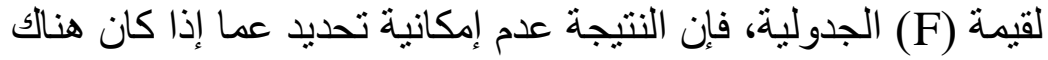
تكامل مشترك بين المتغير ات من عدمه.

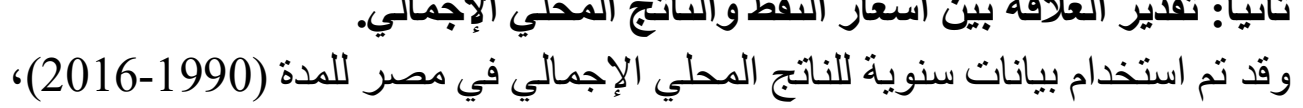

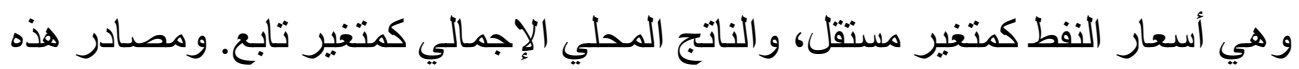

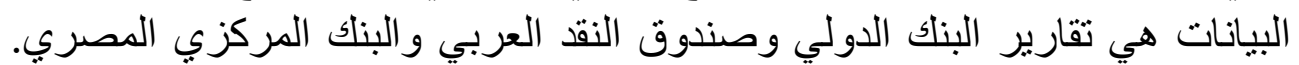
وتم استخدام اللو غاريتمات للتخلب على مشاكل التقدير.

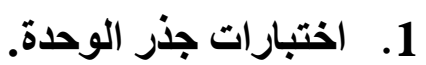

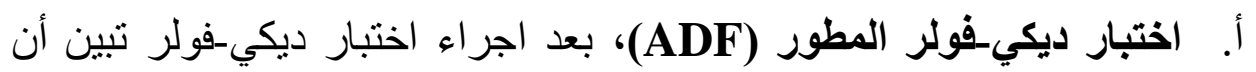

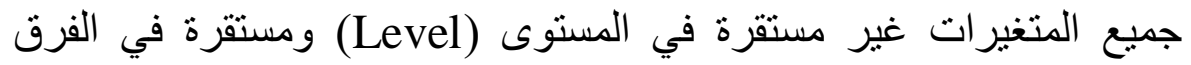
الأول (At First Difference).

Kripfganz, Sebastian, Daniel C. Schneider, ardl: Stata module to estimate autoregressive distributed lag models, Stata Conference, Chicago, July 29, 2016, p.10. 
ب. اختبار فيليبس بيرون (P.P)؛ بعد اجر اء اختبار فيلييس بيرون تبين أن جميع (Levي

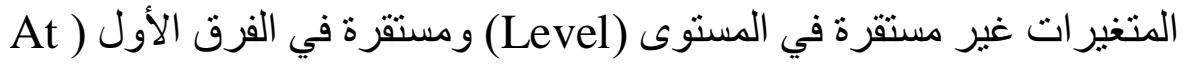

.(First Difference

ويوضح الجدول (3) اختبارات جذر الوحدة، وتشير الرموز الموجودة في الجدول

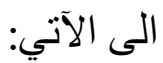

• رمز (*) يشير الى ان المتغير الاقتصادي مستقر عند مستوى (10\%).

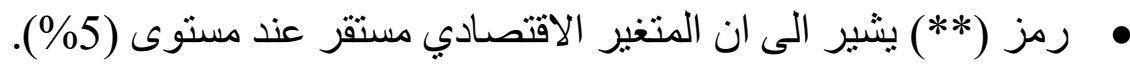

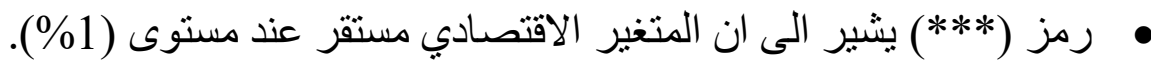

• رمز (No) يشير الى ان المتغير الاقتصادي غير مستقر.

جدول (3): اختبارات جذر الوحدة

\begin{tabular}{|c|c|c|c|c|c|c|c|}
\hline \multicolumn{4}{|c|}{ اختبار ديكي-فولر المطور (ADF) } & \multicolumn{4}{|c|}{ اختبار فيليبس بيرون (P.P) } \\
\hline \multicolumn{2}{|c|}{ المستوى } & GD & $\mathbf{O L}$ & \multicolumn{2}{|c|}{ المستوى } & GD & $\overline{\text { OL }}$ \\
\hline \multirow{3}{*}{ ثابت } & (ADF) & 0.9261 & 1.0403 & \multirow{3}{*}{ ثابت } & (P.P) & 2.1594 & 1.1003 \\
\hline & 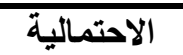 & 0.7627 & 0.7231 & & الاحتمالية & 0.2248 & 0.7 \\
\hline & الاستقرارية & No & No & & الاستقرارية & No & No \\
\hline \multirow{3}{*}{ و ثابت } & (ADF) & $\begin{array}{c}- \\
2.2797\end{array}$ & 1.3842 & \multirow{3}{*}{ واتجاه } & (P.P) & $\begin{array}{c}- \\
2.8182\end{array}$ & 1.3842 \\
\hline & 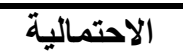 & 0.4282 & $\overline{0.8416}$ & & الاحتمالية & 0.2037 & 0.8416 \\
\hline & الاستقرارية & No & No & & الاستقرارية & No & No \\
\hline \multirow{3}{*}{ واتجات } & (ADF) & 1.1825 & 0.2255 & \multirow{3}{*}{ و ثابت } & $\begin{array}{l}\text { (P.P) } \\
\text { (P. }\end{array}$ & 2.7878 & 0.1886 \\
\hline & 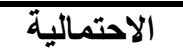 & 0.9344 & 0.7437 & & الاحتمالية & 0.9978 & 0.7329 \\
\hline & الاستقرارية & No & No & & الاستقرارية & No & No \\
\hline \multicolumn{2}{|c|}{ الفرق الأول } & $d(G D)$ & $\begin{array}{l}\mathrm{d}(\mathrm{OL}) \\
\end{array}$ & \multicolumn{2}{|c|}{ الفرق الأول } & d(GD) & $\overline{d(O L)}$ \\
\hline \multirow{3}{*}{ ثابت } & (ADF) & 3.4322 & 4.1965 & \multirow{3}{*}{ ثابت } & (P.P) & 3.4881 & 4.1596 \\
\hline & الاحتمالية & 0.0193 & 0.0033 & & 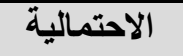 & 0.0171 & 0.0036 \\
\hline & الاستقرارية & *** & **** & & الاستقرارية & ** & **** \\
\hline \multirow{3}{*}{ واتجاه } & (ADF) & -3.382 & -4.176 & \multirow{3}{*}{ و ثابت } & (P.P) & 3.4631 & 4.1334 \\
\hline & الاحتمالية & 0.0766 & 0.0153 & & الاحتمالية & 0.0657 & $\overline{0.0168}$ \\
\hline & الاستقرارية & * & ** & & الاستقر ارية & * & ** \\
\hline بدون & (ADF) & - & - & بدون & (P.P) & - & - \\
\hline
\end{tabular}




\begin{tabular}{|c|c|c|c|c|c|c|c|}
\hline \multirow{3}{*}{ واتجاه } & & 3.4811 & 4.2355 & \multirow{3}{*}{ واتجاه } & & 3.4464 & 4.2132 \\
\hline & الاحتمالية & 0.0012 & 0.0002 & & الاحتمالية & 0.0013 & 0.0002 \\
\hline & الاستقز ارية & $* * *$ & $* * *$ & & الاستقر ارية & $* * *$ & $* * *$ \\
\hline
\end{tabular}

2. اختبارات التكامل المشترك وفق منهجية (ARDL). وتمثل ثناثة اختبار ات و هي اختبار (Bounds Test) الذي يبين وجود التكامل المشترك، و واختبار الذي يبين العلاقة طويلة الاجل، واختبار (Long-run relationship) الذي يبين العلاقة قصيرة الاجل. (Short-run relationship) أ. اختبار (Bounds Test)، اذ اشارت نتائج تقدير العلاقة بين أسعار النفط والناتج المحلي الإجمالي الى وجود تكامل مشترك، حيث كانت قيمة (F-statistic) مستوى معنوية (10.5\%).

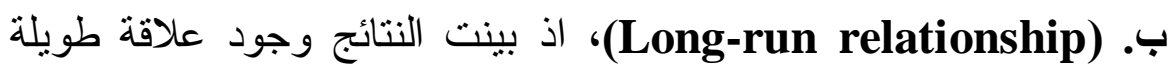
الاجل وموجبة بدرجة احتمالية (0.000) بين أسعار النفط و الناتج المحلي الاجمالي، حيث أنه إذا تغيرت أسعار النفط بمقدار وحدة واحدة فإن الناتج المحلي الإجمالي سيتغير بمقدار (0.85) وحدة، وهذا يتفق مع منطق الإنق

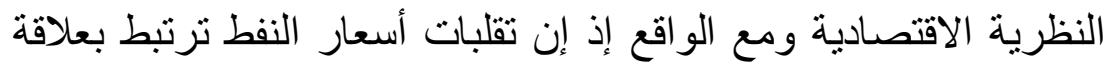

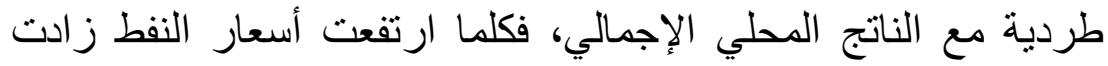
الإير ادات النفطية ومن ثم زيادة حجم الناتج المحلي الإجمالي، وبالعكس الإجس في حالة انخفاض أسعار النفط.

ج. (Short-run relationship)، اذ أظهرت النتائج أنه لا توجد علاقة في الأجل القصير بين تقلبات أسعار النفط الخام والناتج المحلي الإجمالي حيث أن قيمة الاحتمالية هي (0.41) و هي قيمة غير معنوية، أما بالنسبة الإنية لمعلمة تصحيح الخطأ التي تعبر عن سرعة التكيف بين الاجل القئ القصير والاجل الطويل حيث أن الاختلالات في الاجل القصير يتم تصحيحها في في لهي الأجل الطويل و هذه القيمة يجب ان تكون سالبة ومعنوية، فقد كانت قيمتها

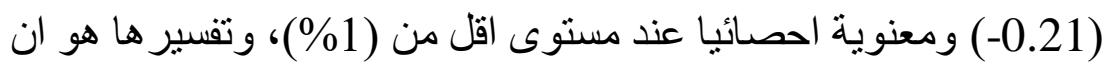

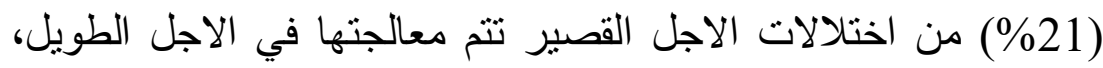

$$
\text { و الجدول (4) يوضح ذلك. }
$$




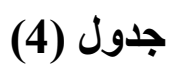

نتائج تقدير المعاملات قصيرة وطويلة الاجل للناتج المحلي الإجمالي

\begin{tabular}{|c|c|c|c|c|}
\hline \multicolumn{5}{|c|}{ ECM Regression } \\
\hline Variable & Coefficient & Std. Error & t-Statistic & Prob. \\
\hline $\bar{C}$ & 0.835914 & 0.214154 & 3.90333 & 0.0009 \\
\hline$\overline{\mathrm{D}(\mathrm{OL})}$ & 0.0541 & 0.064902 & 0.833569 & 0.4144 \\
\hline$\overline{\mathrm{D}(\mathrm{OL}(-1))}$ & -0.03599 & 0.075488 & -0.47677 & 0.6387 \\
\hline CointEq(-1)* & -0.21665 & 0.057799 & -3.74835 & 0.0013 \\
\hline \multicolumn{5}{|c|}{ Long run coefficient } \\
\hline Variable & Coefficient & Std. Error & t-Statistic & Prob. \\
\hline$\overline{\mathrm{OL}}$ & 0.853484 & 0.119253 & 7.156924 & 0.00000 \\
\hline \multicolumn{5}{|c|}{ المعادلة المقارة ( EC = GD - (0.8535*OL } \\
\hline \multicolumn{5}{|c|}{ F-Bounds Test } \\
\hline \multirow{4}{*}{ F-statistic } & \multirow{4}{*}{6.690536} & $10 \%$ & 4.04 & 4.78 \\
\hline & & $5 \%$ & 4.94 & 5.73 \\
\hline & & $2.5 \%$ & 5.77 & 6.68 \\
\hline & & $1 \%$ & 6.84 & 7.84 \\
\hline
\end{tabular}

المصدر: مخرجات برنامج (E-views) الإصدار العاشر.

2. الاختبارات التثخيصية (Diagnostic Tests)، وتشمل ثلاثة

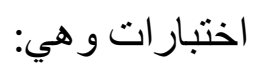

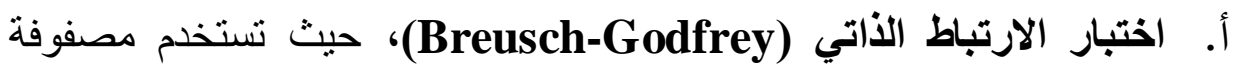
الارتباط الذاتي الخطي البسيط للكسف عن مشكلة الارتباط الذاتي بين

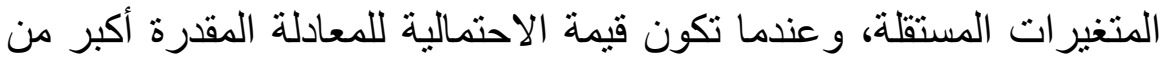

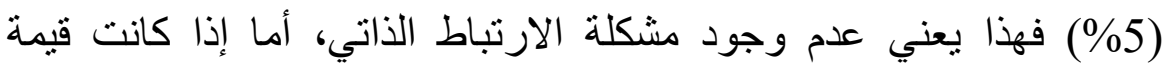

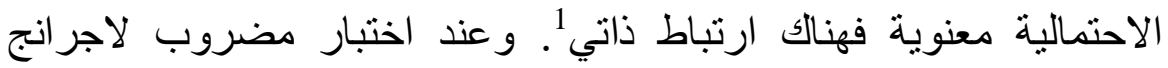

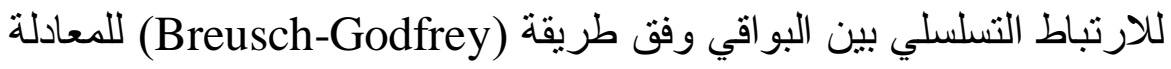

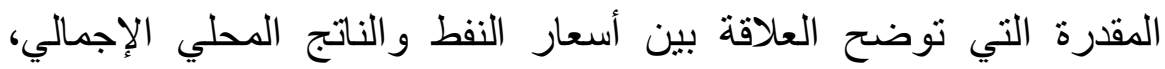
أنشارت النتائج الى عدم معنوية الاختبارات في المعادلة المقدرة لأن قيمة الإنية 
الاحتمالية أكبر من (0.05) وبذلك فإنه لا توجد مشكلة الارتباط الذاتي، وكما

مبين في جدول (5).

ب. اختبار اختلاف التباين أو اختلاف التباين (Heteroskedasticity)، اذ تظهر مشكلة اختلاف التباين عند استخدام بيانات مقطعية في حالة السلاسل

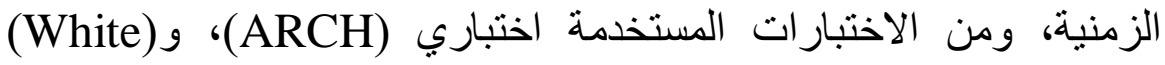

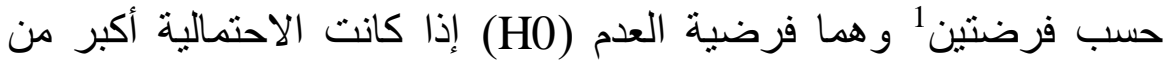

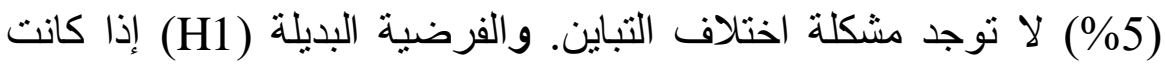

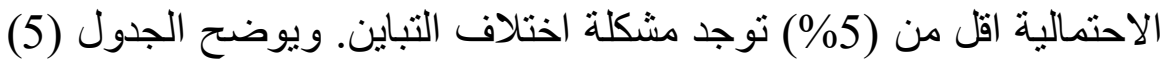

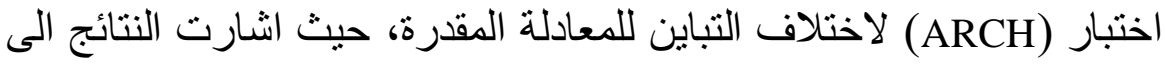

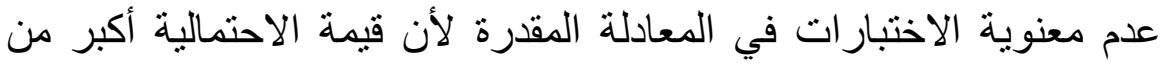
(0.05) وبذلك فإنه لا نو جد مشكلة اختلاف التباين. جدول (5): اختبارات الارتباط الأتي واختلاف التباين

\begin{tabular}{|c|c|c|c|}
\hline \multicolumn{4}{|c|}{ Breusch-Godfrey Serial Correlation LM Test: } \\
\hline F-statistic & 2.325442 & Prob. F(2,18) & 0.1264 \\
\hline $\begin{array}{c}\text { Obs*R- } \\
\text { squared }\end{array}$ & 5.133226 & $\begin{array}{c}\text { Prob. Chi- } \\
\text { Square(2) }\end{array}$ & 0.0768 \\
\hline \multicolumn{4}{|c|}{ Heteroskedasticity Test: ARCH } \\
\hline F-statistic & 0.453625 & Prob. F(1,22) & 0.5076 \\
\hline $\begin{array}{c}\text { Obs*R- } \\
\text { squared }\end{array}$ & 0.484866 & $\begin{array}{c}\text { Prob. Chi- } \\
\text { Square(1) }\end{array}$ & 0.4862 \\
\hline
\end{tabular}

المصدر: مخرجات برنامج (E-views) الإصدار العاشر.

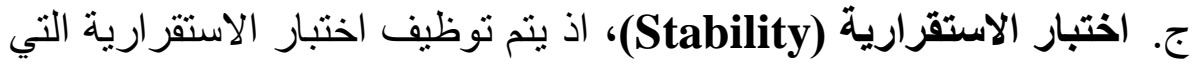

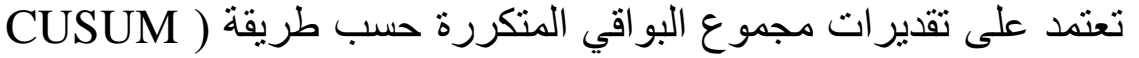

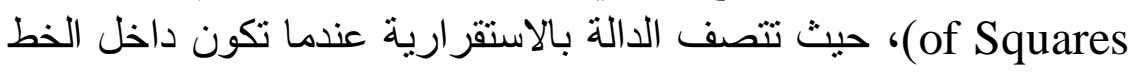

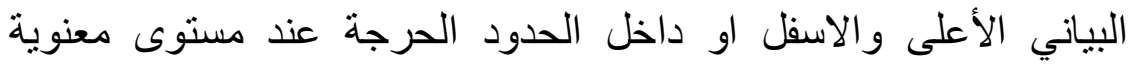

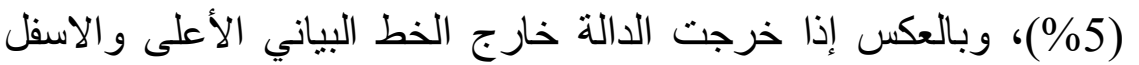

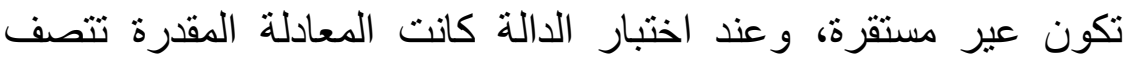
بالاستقر ارية. وكما موضح في الثكل (1). 


\section{شكل (1): اختبارات الاستقرارية}

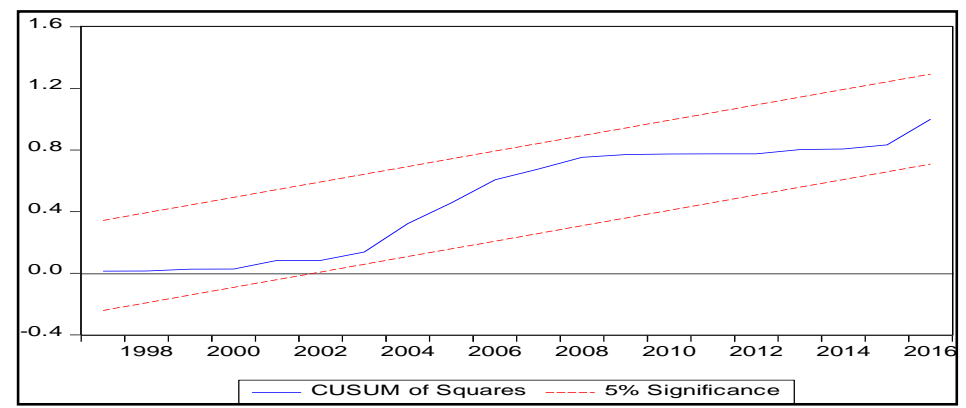

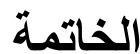

توصل البحث الى عدد من الاستتناجات و التوصيات التي نستعرضها فيما يلي: أولاً: الاستنتاجات.

1. تؤثر تقلبات أسعار النفط بصورة او بأخرى في المتغيرات الاقتصادية الكلية

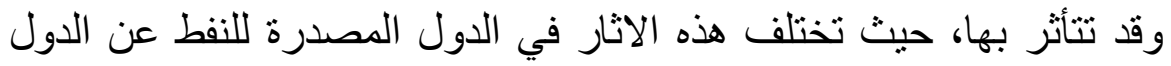
المستهلكة للنفط وفي الأجلين الطويل والقئ القصير.

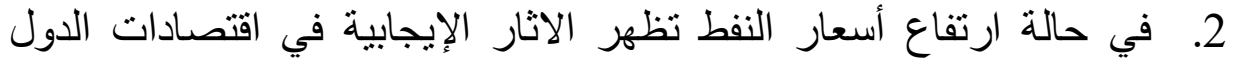

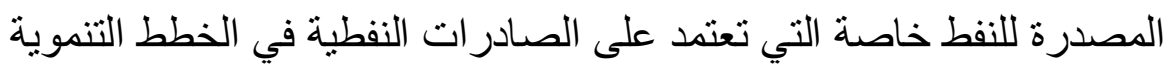

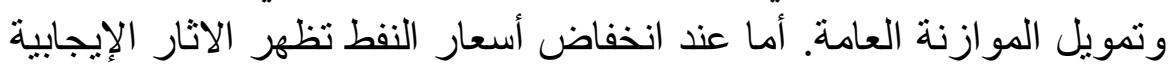

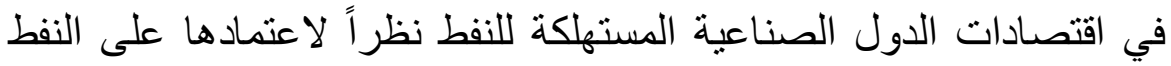

$$
\text { ومشتقاته كأحد أهم أنو الع مدخلات الانتاج. }
$$

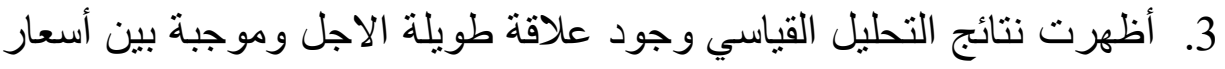

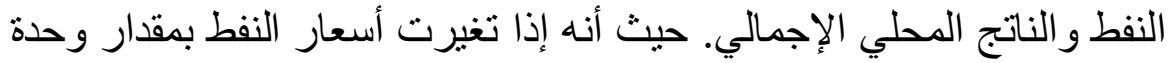

$$
\text { واحدة فإن الناتج المحلي الإجمالي سيتغير بمقدار (0.85) وحدة. }
$$

1. تتويع مصادر الدخل في مصر وزيادة الوعي الضريبي لتمويل الموازنة

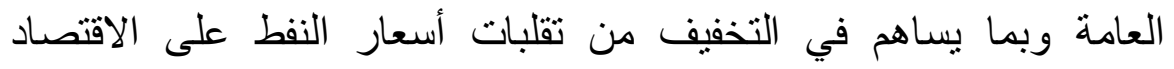

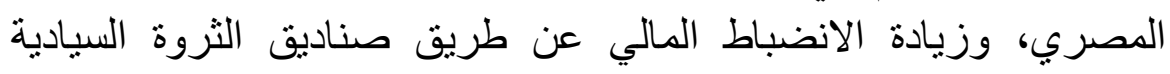
و المشاريع الصغيرة التي تخدم الاقتصاد القومي. 


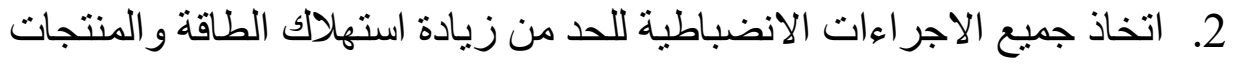

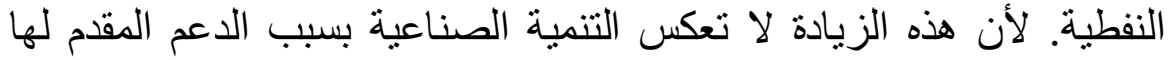

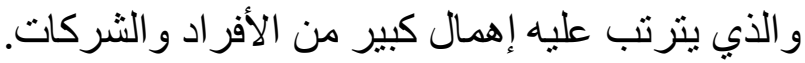
3. رفع احتياطي الطاقة التقليدية المتوفرة بتحسين كفاءة استخدام الآبار النفطية

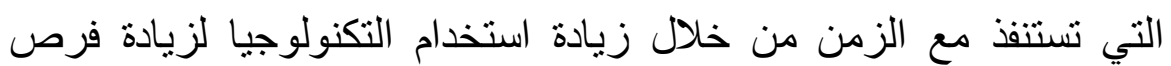
اكتشاف آبار جديدة.

4. استغلال مصادر الطاقة الجديدة والمتجددة مثل الطاقة النووية والطاقة الثمسية وطاقة الرياح. 5. يجب ان يكون هناك في المستقبل المزيد من الدراسات الاكاديمية التي تهتم

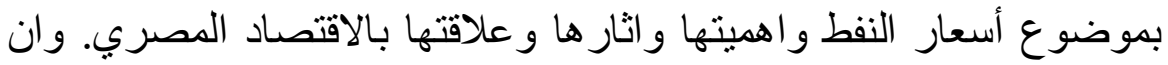
تكون كل در اسة مركزة على قطاع معين بكل متغير اتها

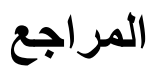

1. ابو الفضل، فتحي واخرون، دور الدولة والمؤسسات في ظل العولمة، الهيئة المصرية العامة للكتاب، الطبعة الأولى، 2004.

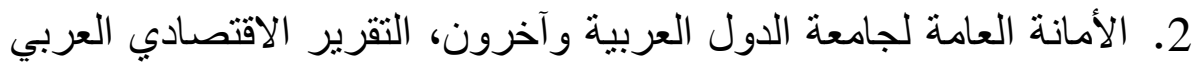

$$
\text { الموحد، للسنوات (2000-2017). }
$$

3. الحسن، تماضر جابر البشير، قياس أثر تقلبات سعر الصرف على ميزان

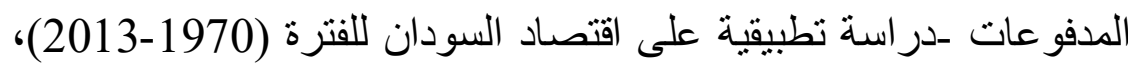

2015 ،Volume 16(2) ،Journal of Economic Sciences 4. الربيعي، عبده محم فاضل، الخصخصة وأثر ها على التنمية بالدول النامية، مكتبة مدبولي، القاهرة، الطبعة الأولى، 2004.

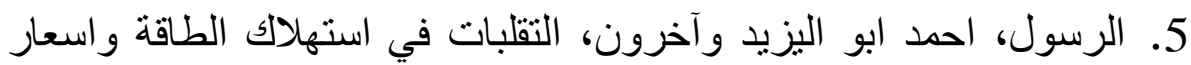
وانتاج النفط و علاقتها بمعدل النمو الاقتصادي بالمملكة العربية السعودية،

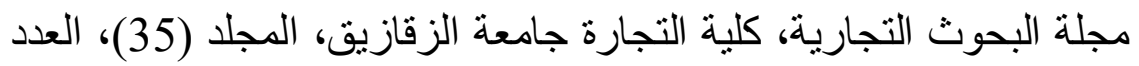

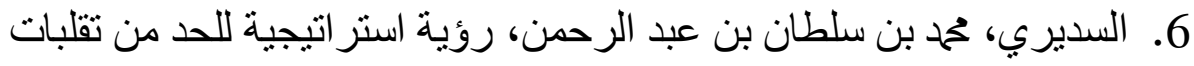
اسعار النفط على الأمن الاقتصادي السعودي، رسالة ماجستير، كلية العندية العلوم الاستراتيجية، جامعة نايف العربية للعلوم الأمنية، المملكة العربية السعودية، 2014

7. العيوطي، حسني ححم، أزمة الجنيه المصري، الجذور.. الحلول ورؤية مصرية جديدة، دار الجمهورية للصحافة، سبتمبر 2004. 
8. المزيني، عماد الدين محمد العوامل التي اثرت على تقلبات أسعار النفط

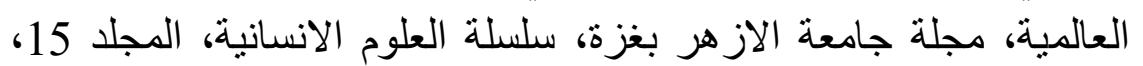

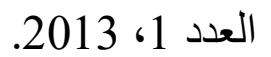

9. الهيتي، احمد حسين علي، بختيار صابر محح، آثر تقلبات الاير ادات النفطية

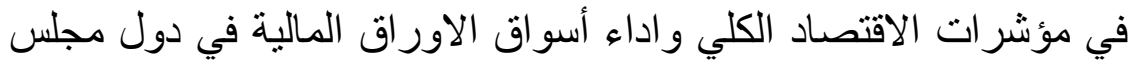
التعاون الخليجي، مجلة جامعة الانبار للعلوم الاقتصادية والإن الادارية، المجلد

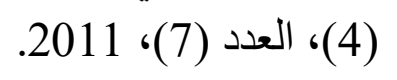

10. بتال، احمد حسين، سراب عبد الكريم مطر، أثر التضخم على عوائد

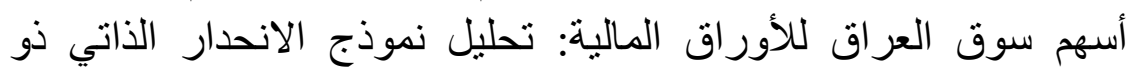

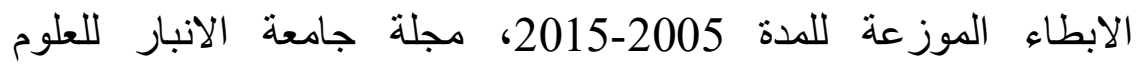

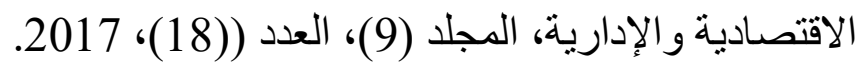
11. تقارير البنك الدولي للأعوام (2010-2017).

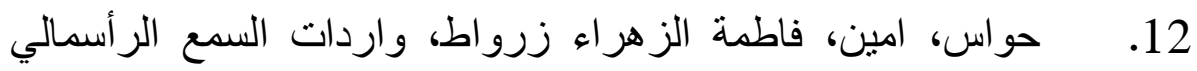

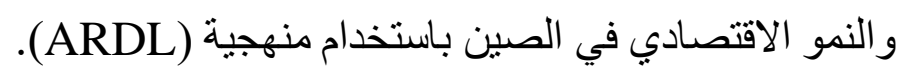

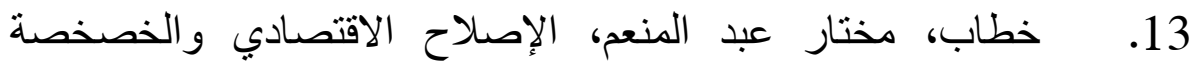

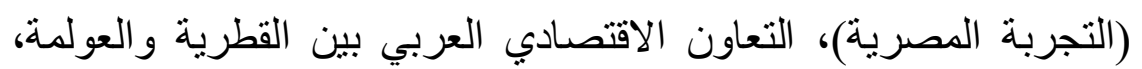
المؤسسة العربية للار اسات و النشر ، 2000.

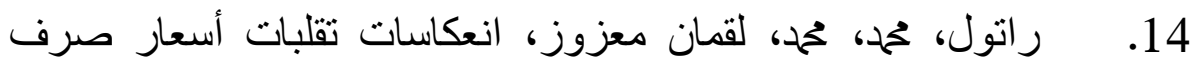

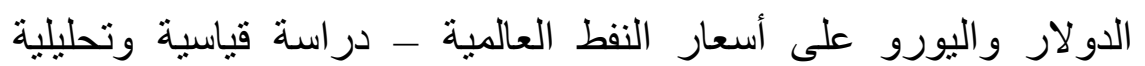

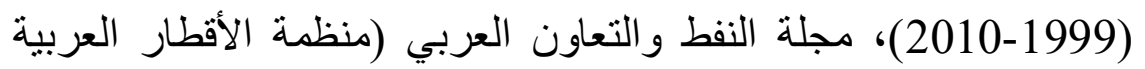
المصدرة للبترول)، الكويت، المجلد (37)، العدد (139)، العزب (139)، 2011.

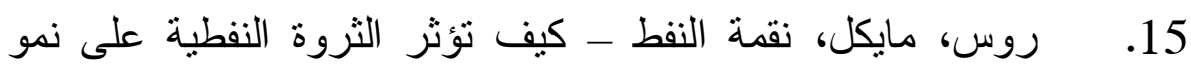

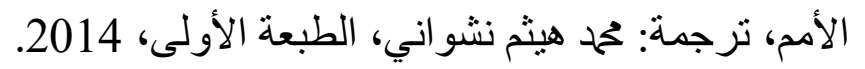

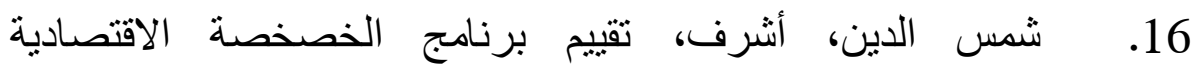
و الاجتماعية لغرب آسيا، الأمم المتحدة، نيو يورئ، برن، 1995.

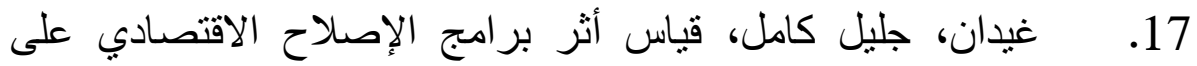

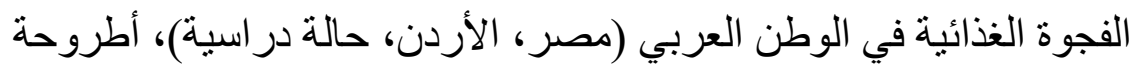

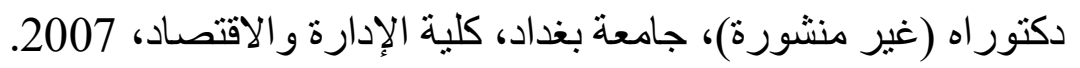

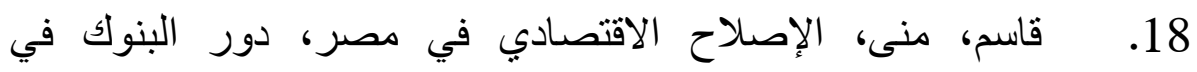
الخصخصة واهم التجارب الدولية، الدار الدصرية اللبنانية، 1998. 


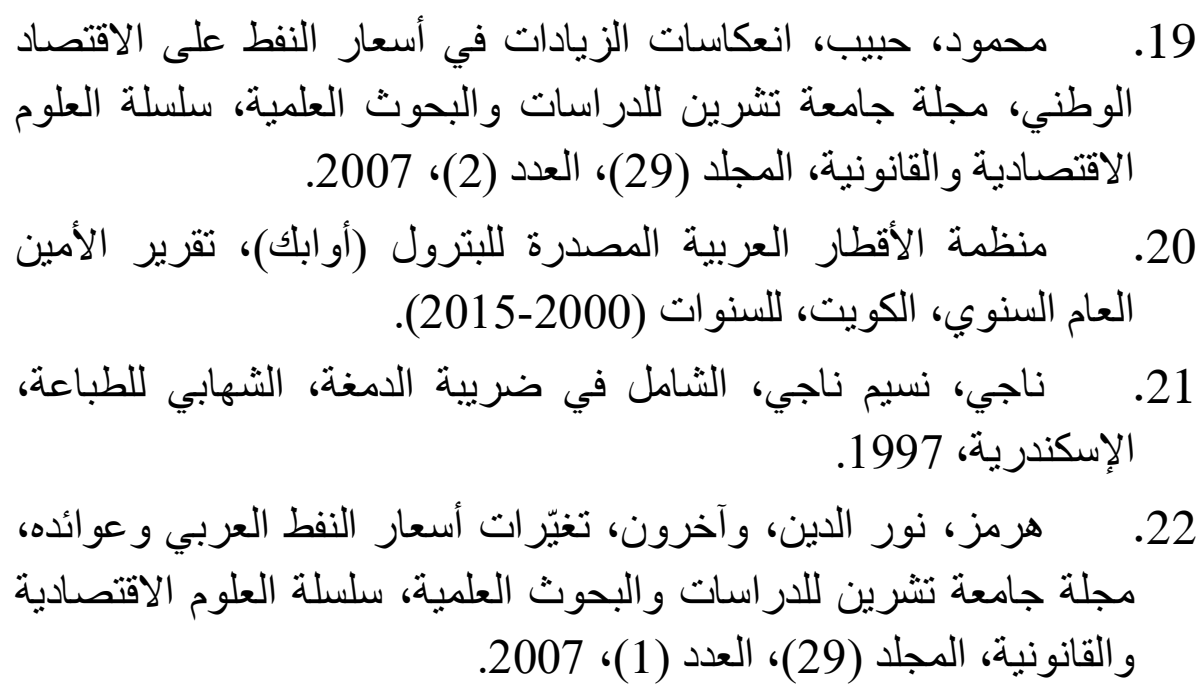

\section{References}

1. Alotaibi, Bader, Oil Price Fluctuations and the Gulf Cooperation Council (Gcc) Countries 1960-2004, PH.D thesis, Southern Illinois University Carbondale, May 2006.

2. Hamuda, Abdulbaset M., et.al, ARDL investment model of Tunisia, Theoretical and Applied Economics, Volume XX (2013), No. 2(579).

3. IMF. Survey, A publication of the international monetary fund, October 28, 1996.

4. korayem, Karima, Adjustment and Reform policies Egypt, Economic and social council , economic and social commission for western Asia , October, 1993.

5. Kripfganz, Sebastian, Daniel C. Schneider, ardl: Stata module to estimate autoregressive distributed lag models, Stata Conference, Chicago, July 29, 2016.

6. Martin Russell, The Russian Economy-Will Russia ever catch up?, EPRS/European Parliamentary Research Service, March 2015.

7. Nkoro, Emeka ,Aham Kelvin Uko, Autoregressive Distributed Lag (ARDL) cointegration technique: application and interpretation, Journal of Statistical and Econometric Methods, vol.5, no.4, 2016.

8. The World Bank, Trends in economic developing countries, World Bank, Washington D.C, 1994. 